\title{
Global height-resolved methane retrievals from the Infrared Atmospheric Sounding Interferometer (IASI) on MetOp
}

\author{
Richard Siddans $^{1,2}$, Diane Knappett ${ }^{1,2}$, Brian Kerridge ${ }^{1,2}$, Alison Waterfall ${ }^{1}$, Jane Hurley ${ }^{1}$, Barry Latter $^{1,2}$, \\ Hartmut Boesch ${ }^{2,3}$, and Robert Parker ${ }^{2,3}$ \\ ${ }^{1}$ STFC Rutherford Appleton Laboratory, Chilton, UK \\ ${ }^{2}$ National Centre for Earth Observation, Leicester, UK \\ ${ }^{3}$ Earth Observation Science, University of Leicester, Leicester, UK \\ Correspondence to: Richard Siddans (richard.siddans@stfc.ac.uk)
}

Received: 6 September 2016 - Discussion started: 9 November 2016

Revised: 23 August 2017 - Accepted: 25 August 2017 - Published: 6 November 2017

\begin{abstract}
This paper describes the global height-resolved methane $\left(\mathrm{CH}_{4}\right)$ retrieval scheme for the Infrared Atmospheric Sounding Interferometer (IASI) on MetOp, developed at the Rutherford Appleton Laboratory (RAL). The scheme precisely fits measured spectra in the 7.9 micron region to allow information to be retrieved on two independent layers centred in the upper and lower troposphere. It also uses nitrous oxide $\left(\mathrm{N}_{2} \mathrm{O}\right)$ spectral features in the same spectral interval to directly retrieve effective cloud parameters to mitigate errors in retrieved methane due to residual cloud and other geophysical variables. The scheme has been applied to analyse IASI measurements between 2007 and 2015. Results are compared to model fields from the MACC greenhouse gas inversion and independent measurements from satellite (GOSAT), airborne (HIPPO) and ground (TCCON) sensors. The estimated error on methane mixing ratio in the lower- and upper-tropospheric layers ranges from 20 to 100 and from 30 to $40 \mathrm{ppbv}$, respectively, and error on the derived column-average ranges from 20 to $40 \mathrm{ppbv}$. Vertical sensitivity extends through the lower troposphere, though it decreases near to the surface. Systematic differences with the other datasets are typically $<10 \mathrm{ppbv}$ regionally and $<5$ ppbv globally. In the Southern Hemisphere, a bias of around $20 \mathrm{ppbv}$ is found with respect to MACC, which is not explained by vertical sensitivity or found in comparison of IASI to TCCON. Comparisons to HIPPO and MACC support the assertion that two layers can be independently retrieved and provide confirmation that the estimated random errors on the column- and layer-averaged amounts are realistic. The data have been made publically available
\end{abstract}

via the Centre for Environmental Data Analysis (CEDA) data archive (Siddans, 2016).

\section{Introduction}

Methane $\left(\mathrm{CH}_{4}\right)$ is one of the most important long-lived greenhouse gases (GHG) in the atmosphere. Its concentration in the troposphere has increased by a factor of around 2.5 since pre-industrial times, mainly as a result of human activity (IPCC, 2013). Currently, natural and anthropogenic sources have similar global annual magnitudes. The largest contributions are from fossil fuel extraction/use, ruminant livestock, decomposition of waste, rice cultivation (all anthropogenic), wetland emissions, geological sources, termites (natural) and biomass burning (both anthropogenic and natural). Current emission estimates are subject to considerable uncertainties (IPCC, 2013; Kirschke, 2013), and prediction into the future is even more uncertain. Large amounts of methane are stored in Arctic permafrost and clathrates on the ocean floor; methane release from these stores, as a result of warming, would lead to a strong positive feedback on climate.

The atmospheric abundance of methane is determined by surface emissions balanced by chemical sinks, predominantly via reaction with hydroxyl radical. Between 1999 and 2006 there was little growth in the annually averaged global methane concentration, but since then a significant increase of around 5 ppbv year $^{-1}$ has been observed at surface level 
(Rigby, 2008; Sussman, 2012). The reasons for this recent behaviour are not yet clear (Nisbet, 2014).

Global observations from nadir-viewing satellite sensors can now provide information to complement and extend that available from surface in situ and remote-sensing measurements to improve our knowledge of the processes controlling the atmospheric distribution of methane and to monitor its variability on a decadal scale. Methane can be measured remotely using bands in the shortwave infrared (SWIR) and thermal infrared (TIR). Observations in the SWIR, such as those from SCIAMACHY on Envisat (Buchwitz, 2005; Frankenberg, 2010) and GOSAT TANSO Fourier transform spectrometer (FTS) (Butz, 2010; Parker, 2011 and Yoshida, 2013), provide information on column-averaged methane with a vertical sensitivity, in cloud-free conditions over most land surfaces, which is close to uniform throughout the atmospheric column. Such measurements rely on surfacereflected sunlight, so observations are limited to daytime and predominantly over land (ocean reflectance being too low except in sun-glint geometry). TIR measurements of methane are available from spectrometers including AuraTES (Worden, 2012), Aqua-AIRS (Xiong, 2008) and MetOp IASI (Razavi, 2009; Crevoisier, 2009, 2013; Xiong, 2013). These complement the SWIR observations with regard to both vertical sensitivity and geographical-temporal coverage. Because TIR spectral signatures depend on thermal contrast between the atmosphere and surface, sensitivity tends to be strong in the mid to upper troposphere and relatively low near the surface. TIR measurements are made over both land and sea and during day and night. The spatial sampling of IASI is much greater than that of GOSAT (the only currently operating SWIR methane sensor following the loss of Envisat in 2012): IASI provides 1.3 million soundings per day (with $12 \mathrm{~km}$ diameter footprint at nadir), over a sufficiently wide swath to provide approximately even sampling of all longitudes (Clerbaux, 2009). IASI is currently flying on both MetOp-A (since 2006) and B (since 2012), effectively doubling the spatial sampling. EUMETSAT plans MetOpC to take over from MetOp-A around 2018, to be followed by IASI Next Generation on the MetOp second-generation series from 2022 to 2040, yielding a self-consistent global dataset from 2007 onwards. In contrast, GOSAT typically provides of order 1000 soundings per day $(10.5 \mathrm{~km}$ diameter footprint) over a relatively narrow swath about the 14 ground tracks (Kuze, 2016; Crisp, 2012). The potential for TIR and SWIR observations to be used together to infer near-surface methane concentrations is studied in Worden et al. (2015). Once in orbit, the Sentinel-5 Precursor (S5P), and later Sentinel 5, will offer SWIR methane measurements with much improved spatial sampling compared to earlier SWIR sensors.

This paper describes the global height-resolved methane retrieval scheme developed at the Rutherford Appleton Laboratory (RAL). Key aspects of the scheme include
- retrieval of two independent pieces of information on the methane profile in the upper and lower troposphere by precisely fitting measured spectra in the 1232$1288 \mathrm{~cm}^{-1}$ interval;

- use of nitrous oxide $\left(\mathrm{N}_{2} \mathrm{O}\right)$ spectral features in the same interval, coupled to modelling of the $\mathrm{N}_{2} \mathrm{O}$ distributions (as described in Sect. 2.4), to estimate effective cloud parameters, which mitigate errors in retrieved methane due to residual cloud and other geophysical variables affecting radiative transfer. While existing schemes (Razavi, 2009; Worden, 2012) also exploit the fact that $\mathrm{N}_{2} \mathrm{O}$ retrievals from the same spectral range as $\mathrm{CH}_{4}$ are affected similarly by residual cloud contamination, temperature and other errors, their approaches involve jointly retrieving $\mathrm{N}_{2} \mathrm{O}$ with other fit parameters (including methane and cloud). In the RAL scheme the $\mathrm{N}_{2} \mathrm{O}$ profile at every location is fixed. Information from IASI measurements at spectral locations of $\mathrm{N}_{2} \mathrm{O}$ lines is thereby used for co-retrieval of cloud (and other) parameters and not $\mathrm{N}_{2} \mathrm{O}$.

A neural-network scheme developed by Crevioissier (2009) has been applied to measurements in 10 IASI channels between 1301 and $1305 \mathrm{~cm}^{-1}$ (together with co-located microwave observations for temperature and humidity sounding). Those channels were chosen to minimise sensitivity to $\mathrm{N}_{2} \mathrm{O}$. Methane is retrieved at tropical latitudes in a single layer, with sensitivity to the mid-troposphere and above (peak sensitivity $\sim 230 \mathrm{hPa}$ ). IASI methane data produced by that scheme have been adopted for the EC's MACC project (Massert, 2014) and for ESA's CCI project (Buchwitz, 2015). By more extensively exploiting IASI measurements in the 7.8-8 micron range and modelling radiative transfer online, the RAL scheme reported here provides information extending into the lower troposphere and with near-global coverage.

\section{Data processing scheme}

\subsection{Optimal estimation}

The scheme is based on the optimal estimation method (Rodgers, 2000), which solves an otherwise underconstrained inverse problem by introducing prior information. This method finds the optimal state vector $\boldsymbol{x}$ (which contains the parameters we wish to retrieve) by minimising a cost function:

$\chi^{2}=(\boldsymbol{y}-F(\boldsymbol{x}))^{\mathrm{T}} \mathbf{S}_{y}^{-1}(\boldsymbol{y}-F(\boldsymbol{x}))+(\boldsymbol{a}-\boldsymbol{x})^{\mathrm{T}} \mathbf{S}_{a}^{-1}(\boldsymbol{a}-\boldsymbol{x})$,

where $\boldsymbol{y}$ is a vector containing each IASI spectral brightness temperature (BT) measurement used by the retrieval; $\mathbf{S}_{y}$ is a covariance matrix describing the errors on the measurements; $F(\boldsymbol{x})$ is the forward model (FM), which predicts measurements given $\boldsymbol{x}$; and $\mathbf{S}_{a}$ is the a priori covariance matrix, which describes the assumed errors in the a priori estimate of the state, $\boldsymbol{a}$. As the FM is non-linear with respect 
to perturbations in methane and other elements of the state vector, the solution state needs to be found iteratively. In this case we adopt the well-known Levenberg-Marquardt method (summarised in Press, 1995), assuming convergence to have occurred when the change in cost-function value is smaller than 1 .

\subsection{Measurements}

IASI (Blumstein, 2004) provides spectra at $0.5 \mathrm{~cm}^{-1}$ apodized resolution, sampled every $0.25 \mathrm{~cm}^{-1}$, from 625 to $2760 \mathrm{~cm}^{-1}$. Spectra are measured with four detectors, each with a circular field of view on the ground (at nadir) of approximately $12 \mathrm{~km}$ diameter, arranged in a $2 \times 2$ grid within a $50 \times 50 \mathrm{~km}^{2}$ field of regard (FOR). IASI scans to provide 30 FORs (120 individual spectra) evenly distributed across a $2200 \mathrm{~km}$ wide swath. Our retrieval scheme uses measurements between 1232.25 and $1288.00 \mathrm{~cm}^{-1}$, chosen following the work of Razavi (2009) to (a) minimise errors caused by neglecting line mixing in the forward model and (b) include channels with relatively clear transmission to the ground, to help constrain co-retrieved cloud parameters and surface temperature. Channels between 1245-1246.75 and 1267$1270 \mathrm{~cm}^{-1}$ are omitted to avoid problematic spectral features (in the former range attributed to line-mixing effects).

The noise on individual IASI spectra is particularly low in this spectral range (Hilton, 2012), with noiseequivalent brightness temperature (NEBT) around $0.07 \mathrm{~K}$ (for a reference scene temperature of $280 \mathrm{~K}$ ), corresponding to a noise-equivalent spectral radiance (NESR) of $5.8 \mathrm{nW} /\left(\mathrm{cm}^{2} \mathrm{srcm}^{-1}\right)$. Early retrievals from this range revealed a significant contribution from scene photon noise, so we adopt the following in-house model of the estimated error in each channel:

$\Delta y_{\text {noise }}=\sqrt{h+o \bar{I}}$

where parameters $o$ and $h$ are constants derived empirically from an analysis of the random component of fit residuals in this range (from an early version of the retrieval scheme) and $\bar{I}$ is the mean spectral radiance over the complete IASI band. This yields NESR values ranging from 3 to $10 \mathrm{nW} /\left(\mathrm{cm}^{2} \mathrm{srcm}^{-1}\right)$ over the typical range of bandaveraged measured radiances.

\subsection{Forward model}

RTTOV version 10 (Matricardi, 2009) is the basis of the RAL FM. RTTOV estimates radiances convolved with the IASI spectral response function by use of spectrally averaged layer transmittances, based on a fixed set of coefficients which weight atmospheric-state-dependent predictors. The RTTOV v10 model is sufficiently fast to enable global processing of the IASI mission with modest computational resources. In order to allow interference from the water vapour isotopologue HDO to be modelled adequately, this is handled as an independent variable to the major isotopologue $\mathrm{H}_{2}^{16} \mathrm{O}$. We have derived coefficients specifically for this spectral range, by running the line-by-line Reference Forward Model (RFM) (Dudhia, 2016) using HITRAN 2008 (Rothman, 2009) spectroscopic line data for the same set of atmospheric profiles and predictors used in Matricardi (2009), with the exception that predictors of the type used for $\mathrm{CO}$ are used instead to predict HDO transmittances. The accuracy of the RTTOV model with the new HDO coefficients is tested by comparing radiances from $\mathrm{RTTOV}$ to those calculated directly with the RFM for an independent set of atmospheric profiles. The mean and standard deviation (SD) of these differences are generally found to be $<0.05 \mathrm{~K}$, though SDs can exceed $0.2 \mathrm{~K}$ in a few spectral channels particularly where water vapour transmittances are comparable to those of another variable gas. This source of FM error is accounted for in the retrieval by adding the RTTOV-RFM variances to the diagonals of the IASI measurement error covariance matrix $\left(\mathbf{S}_{y}\right)^{1}$.

The ECMWF ERA-Interim (Dee, 2011) reanalysis is used to define the atmospheric temperature profile and the surface pressure appropriate for each IASI scene. Reanalysis fields are provided at 6-hourly intervals, approximately $0.7^{\circ}$ horizontal resolution, on 60 vertical levels. These fields are linearly interpolated to the IASI location and time. Profiles of methane and water vapour (including the isotopologue HDO) are defined by the retrieval state vector (see below), as is the surface (skin) temperature.

Over sea, the RTTOV sea surface emissivity model is used. Over land, the retrieval scheme currently uses the University of Wisconsin surface emissivity database (Seeman, 2008). Principal components of an ensemble of measured land surface spectral emissivity spectra are used in conjunction with $0.1^{\circ}$ latitude-longitude gridded monthly data from MODIS to generate global maps of surface spectral emissivity.

It is found that fits to measured spectra based on this $\mathrm{FM}^{2}$ lead to residuals (i.e. differences between observed and modelled spectra) which are small ( $<0.5 \mathrm{~K} \mathrm{RMS})$ but still significant compared to the IASI NEBT (see Sect. 2.2). Columnaveraged mixing ratios derived from retrieved methane profiles are positively biased compared to independent measurements by approximately $4 \%$, with a systematic heightdependent structure in the profile ${ }^{3}$. A comparable bias has

\footnotetext{
${ }^{1}$ Spectral correlations in the RTTOV error are neglected. In practise this is adequate, as error correlations are found to be weak for the few channels in which this error is large in comparison to the noise.

${ }^{2}$ We refer here to fits by the FM implemented in a manner identical to that described in this paper, with the exception that points 1-3 above were not applied, i.e. ERA-Interim temperature profiles and University of Wisconsin emissivities are used and methane and other state vector elements are retrieved as described in Sect. 2.5.

${ }^{3}$ The bias on column-averaged mixing ratio was estimated from comparisons of a version of the retrieval, which did not apply points $1-3$, to TCCON and GOSAT. These were carried out in an identical fashion to that described in Sects. 5.3 and 5.4 below. Errors in
} 
been found in TES retrievals, which exploit the same spectral range (Worden, 2012; Alvaredo, 2015), although with a different height dependence and in MIPAS stratospheric retrievals in limb geometry as well (Von Clarmann, 2009). These similarities suggest a possible common underlying cause, which could likely be related to spectroscopic line parameters. To perform a preliminary assessment, retrievals have been carried out with the RFM or LBLRTM line-byline radiative transfer model in place of RTTOV and adopting either HITRAN 2008 or 2012 line data. LBLRTM includes an approximate treatment of line mixing (Alvaredo, 2013). Since none of these tests led to a significant reduction in the positive bias with respect to independent (from the Total Carbon Column Observing Network, TCCON) data, an in-depth investigation of spectroscopic line parameters can be inferred to be desirable to reconcile satellite methane retrievals in the relevant TIR and SWIR bands. For expediency, an empirical approach has been adopted to account for the identified bias, on the assumption that it is inherent to RTTOV as implemented in our IASI retrieval scheme:

1. When input to RTTOV, all methane mixing ratios are multiplied by a factor of 1.04 compared to the values in the state vector (i.e. the FM assumes $4 \%$ more methane than is ultimately reported as the retrieved value).

2. Spectral mean residual patterns derived from applying the retrieval scheme to 1 day of IASI data over cloud-free ocean in the latitude range of 75 to $15^{\circ} \mathrm{S}$ are adopted to represent the mean forward model error and its scan-angle dependence. In this version of the scheme, rather than retrieve a height-resolved profile, the methane profile shape is specified, using a similar approach to that adopted to define $\mathrm{N}_{2} \mathrm{O}$, and a single scale factor is retrieved. The resulting mean residual spectrum from the nadir view, $\boldsymbol{r}_{0}$, has negligible correlation with the spectral weighting function for the altitude-independent scaling of the methane profile. The scan-angle-dependent component of the FM error is estimated as $\boldsymbol{r}_{1}=\boldsymbol{r}_{\mathrm{E}}-\boldsymbol{r}_{0}$, where $\boldsymbol{r}_{\mathrm{E}}$ is the mean residual from both outer edges of the swath.

3. To retrieve global methane, a version of the FM which accounts for the spectral mean residual by adjusting the measurement vector as

$\boldsymbol{y}=\boldsymbol{y}_{\mathrm{RTTOV}}+f_{0} \boldsymbol{r}_{0}+f_{1} \boldsymbol{r}_{1}$,

where $\boldsymbol{y}_{\text {RTTOV }}$ is the radiance vector predicted by RTTOV and factors $f_{0}$ and $f_{1}$ are co-retrieved with methane and other parameters in the state vector, on a scene-by-scene basis.

profile shape were inferred on the assumption that the tropospheric mixing ratio should (on average) be independent of height in Southern Hemisphere mid-latitudes.
It is noted that spatial variations in retrieved values of $f_{0}$ suggest that the mean residual features are at least partly related to the water vapour distribution.

\subsection{Modelling $\mathrm{N}_{2} \mathrm{O}$}

A distinguishing feature of the RAL scheme is the approach developed to specify the $\mathrm{N}_{2} \mathrm{O}$ vertical profile at each IASI measurement location for use in the FM. $\mathrm{N}_{2} \mathrm{O}$ is modelled so that its spectral features can be exploited to co-retrieve two effective cloud parameters and thereby mitigate related errors on the retrieved methane. In the troposphere, $\mathrm{N}_{2} \mathrm{O}$ exhibits variations with latitude and season smaller than $\sim 0.5 \%$ (IPCC, 2013); approximately an order of magnitude smaller than those of methane. The annual growth rate of $\mathrm{N}_{2} \mathrm{O}$ since IASI became operational in 2007 (around $0.23 \%$ year $^{-1}$ ) has been much more consistent than that of methane in recent decades. Mixing ratios of both $\mathrm{N}_{2} \mathrm{O}$ and methane decrease with height in the stratosphere. In the case of $\mathrm{N}_{2} \mathrm{O}$, the decrease commences at lower altitude and is steeper than for methane $e^{4}$. It is therefore particularly important to accurately model the stratospheric $\mathrm{N}_{2} \mathrm{O}$ profile pertaining to individual IASI observations. The lifetime of $\mathrm{N}_{2} \mathrm{O}$ in the stratosphere is such that spatial and day-to-day variability is controlled by dynamics and can therefore be modelled accurately by exploiting the strong correlation, on potential temperature surfaces, between $\mathrm{N}_{2} \mathrm{O}$ and potential vorticity. This is implemented in the RAL scheme using the seasonal $\mathrm{N}_{2} \mathrm{O}$ climatology derived from the ACE-FTS solar occultation sensor (Jones, 2012), which is expressed as a function of equivalent latitude (Lary, 1995) and pressure. This is filled below the tropopause with a fixed mixing ratio of $322 \mathrm{ppbv}$, a representative value for the global mean at the beginning of 2009. The zonal mean field is linearly interpolated to the day of year of a given IASI observation. The $\mathrm{N}_{2} \mathrm{O}$ vertical profile at the locations of individual IASI observations is estimated using the local equivalent latitude, derived from potential vorticity and potential temperature given by the ERA-Interim reanalysis. The long-term, monotonic growth rate in $\mathrm{N}_{2} \mathrm{O}$ is modelled by scaling each derived profile by the factor: $f=1+0.0023 d$, where $d$ is the number of elapsed days since the beginning of 2009.

\subsection{Selection of IASI observations for processing}

The BT difference between the IASI observation in a window channel $\left(950 \mathrm{~cm}^{-1}\right)$ and that simulated on the basis of ERAInterim, assuming clear-sky conditions, is used to screen out scenes which are strongly affected by cloud. If this difference (observation - simulation) is outside the range of -5 to $15 \mathrm{~K}$, the scene is not processed. Furthermore, only scenes having a BT larger than $240 \mathrm{~K}$ in the same channel are currently processed, since (a) the retrieval information content

\footnotetext{
${ }^{4}$ In the case of $\mathrm{N}_{2} \mathrm{O}$, the decrease with height is due to UV photolysis whereas for methane $\left(\mathrm{CH}_{4}\right)$ it is due to reaction with $\mathrm{O}\left({ }^{1} \mathrm{D}\right)$.
} 
is significantly degraded over very cold surfaces (see below) and (b) convergence is often found to be slow in these conditions, leading to a disproportionate use of computational effort.

The IASI MetOp-A orbits from 29 May 2007 to 17 November 2015 have all been processed with this approach, selecting from the four pixels in each FOR the IASI pixel with the warmest BT at $950 \mathrm{~cm}^{-1}$.

\subsection{State vector and a priori constraint}

The state vector for the retrieval scheme consists of 34 elements, as follows:

- Methane mixing ratio (in ppmv, relative to dry air) defined on 12 fixed pressure levels corresponding to $z^{*}$ values of $0,6,12,16,20,24,28,32,36,40,50$ and $60 \mathrm{~km}$, where $z^{*}$ is a simple transformation of pressure, $p$ (in $\mathrm{hPa}$ ), to approximate geometric altitude $(\mathrm{km})$ :

$z^{*}=16\left(3-\log _{10} p\right)$.

The prior state is defined to be a fixed value of $1.75 \mathrm{ppmv}$ in the troposphere, broadly representative of Southern Hemisphere mid-latitudes in 2009, and an annual average height-latitude cross section in the stratosphere. The zonal mean is calculated by averaging into $5^{\circ}$ latitude bins 2 years (September 2008-2010) of output from the TOMCAT chemical transport model run into which ACE-FTS observations of long-lived stratospheric tracers have been assimilated (Chipperfield, 2002). A priori error statistics are estimated as the root-mean-square combination of the SD of the model methane field about its zonal mean and $10 \%$ of the a priori value itself. The model SDs in the troposphere are around $5 \%$, so a priori errors in the troposphere are set to $175 \mathrm{ppbv}$ (i.e. $10 \%$ of the prior value), increasing (in fractional terms) above the tropopause up to peak values of around $50 \%$. The prior state and errors are interpolated in latitude to the location of a given IASI observation. To help regularise the retrieval, off-diagonal elements are defined, assuming a Gaussian function in the vertical with full-width half-maximum $6 \mathrm{~km}$ (in $z^{*}$ units). Here we make a deliberate choice to define a simple and relatively weak constraint to emphasise the vertically resolved information in the IASI measurements. A tighter constraint, which could be justified based on climatological variability, is not necessary to regularise the retrieval and would increase the bias towards the prior (already evident towards high latitudes from the evaluation reported below).

- Natural logarithm of the water vapour $\left(\mathrm{H}_{2} \mathrm{O}\right)$ mixing ratio (in ppmv) defined on 16 fixed pressure levels corresponding to $z^{*}$ values of $0,1,2,3,4,5,6,8,10,12,16$, $20,30,40,50$ and $60 \mathrm{~km}$. The a priori profiles for water vapour are taken from ECMWF analysis, interpolated (linearly) onto these pressure levels. The a priori error covariance is intended to represent (conservatively) errors in the analysis and those associated with interpolation to the time and location of an individual IASI observation:

$\mathbf{S}_{a: \mathrm{H}_{2} \mathrm{O}}=\mathbf{S}_{\mathrm{bg}}+\mathbf{S}_{\mathrm{d} t}+\mathbf{S}_{\mathrm{d} x}$,

where $\mathbf{S}_{\mathrm{bg}}$ is the ECMWF model background error covariance matrix taken from (Collard, 2007); $\mathbf{S}_{\mathrm{d} t}$ is the covariance of differences (considering all profiles in a given day) between ECMWF profiles at one of the 6-hourly analysis times and those at the next analysis time; and $\mathbf{S}_{\mathrm{d} x}$ is the analogous covariance of differences between neighbouring spatial grid points. This results in a covariance matrix with relatively large diagonal elements (corresponding to SDs of up to $60 \%$ peaking in the mid-troposphere) but sufficient vertical correlation to regularise the retrieval.

- Scale factor for HDO, with a priori value of 1 and assumed prior error of 1 . This defines the HDO profile assumed in the FM as follows:

$\boldsymbol{r}_{\mathrm{HDO}}(p)=f_{\mathrm{HDO}} f_{\mathrm{std}} \boldsymbol{r}_{\mathrm{H}_{2} \mathrm{O}}(p)$,

where $f_{\mathrm{HDO}}$ is the retrieved factor, $f_{\text {std }}$ is the (fixed) ratio of HDO : $\mathrm{H}_{2}^{16} \mathrm{O}$ assumed by HITRAN $\left(3.107 \times 10^{-4}\right)$ and $\boldsymbol{r}_{\mathrm{H}_{2} \mathrm{O}}(p)$ is the (retrieved) water vapour main isotope mixing ratio profile.

- Natural logarithm of the (effective) cloud fraction and the associated cloud pressure ( $\mathrm{hPa}$ ). Cloud is modelled in RTTOV as a black body at the given atmospheric level, occupying a given geometric fraction of the scene. The a priori cloud fraction is assumed to be 0.01 (before converting to $\log$ ) and the a priori error is assumed to be 10 (which, given the log representation, is a fractional error of $1000 \%$ with respect to the prior value of 0.01 ). The a priori cloud pressure is $500 \mathrm{hPa}$, with error $500 \mathrm{hPa}$. The logarithm is used as it is found to lead to more stable convergence (non-physical states with negative cloud fraction can otherwise arise during the costfunction minimisation).

- Surface temperature, with a priori value taken from ECMWF analysis and assumed a priori error of $5 \mathrm{~K}$.

- The two scale factors for systematic residuals. A priori values are 1 for $f_{0}$ and 0 for $f_{1}$. Both are assigned an a priori error of 1 . Results from this retrieval scheme are compared below to an earlier version of the scheme, which is identical except that (i) the two cloud parameters are not retrieved (scenes passing the initial cloud test are assumed cloud free) and (ii) the $\mathrm{N}_{2} \mathrm{O}$ profile is jointly retrieved, rather than being modelled. The $\mathrm{N}_{2} \mathrm{O}$ 
prior state and errors are defined in the same way as methane, except that the profiles are scaled, by the same factor at all altitudes, to give a peak mixing ratio in the troposphere of $0.319 \mathrm{ppmv}$.

\section{Error analysis and retrieval characterisation}

The error covariance of the solution from an optimal estimation retrieval is given by

$\mathbf{S}_{x}=\left(\mathbf{S}_{a}^{-1}+\mathbf{K}^{\mathrm{T}} \mathbf{S}_{y}^{-1} \mathbf{K}\right)^{-1}$,

where $\mathbf{K}$ is the weighting function matrix which contains the derivatives of the FM with respect to each element of the (solution) state vector. The square roots of the diagonal elements of this matrix are referred to as the estimated SD (ESD) of each element of the state vector.

The transformation from the retrieved methane mixing ratio profile, $\boldsymbol{x}$, to the dry-air column-averaged mole fraction, $c$, is expressed as a matrix operation $c=\mathbf{M} \boldsymbol{x}$, where $\mathbf{M}$ contains the weights required to perform the linear operations to (i) interpolate the profile defined on the state vector grid to the finer grid used in the radiative transfer model, (ii) integrate to give the total column amount and (iii) normalise by the total column of air. The ESD of the column average is then given by

$\Delta c=\sqrt{\mathbf{M S}_{x} \mathbf{M}^{\mathrm{T}}}$.

The sensitivity of the retrieval to perturbations in the measurement is given by the gain matrix, $\mathbf{G}=\mathbf{S}_{x} \mathbf{K}^{\mathrm{T}} \mathbf{S}_{y}^{-1}$. The sensitivity of the retrieval to perturbations in the true state vector is characterised by the averaging kernel, $\mathbf{A}=\mathbf{G K}$.

$\mathbf{S}_{x}$ can be divided into two terms:

$\mathbf{S}_{x}=\mathbf{S}_{\mathrm{n}}+\mathbf{S}_{\mathrm{s}}$,

where $\mathbf{S}_{\mathrm{n}}=\mathbf{G S}_{y} \mathbf{G}^{\mathrm{T}}$ describes the uncertainty due to measurement errors (characterised by $\mathbf{S}_{y}$ ) and $\mathbf{S}_{\mathrm{s}}=(\mathbf{I}-\mathbf{A}) \mathbf{S}_{a}(\mathbf{I}-$ A) ${ }^{\mathrm{T}}$ describes the smoothing error, i.e. departure from the true state caused by the tendency of the retrieval towards the imposed a priori constraint. As discussed in von Clarrman (2013), the smoothing error only applies to the profile as represented on the (rather coarse) retrieval grid. A consequence of this is that the ESD of the column average from Eq. (8) does not fully capture errors arising from the insensitivity of the retrieval to fine-scale perturbations in the vertical profile. Since methane is well mixed in the troposphere, this issue will often be of little consequence, although there will be a tendency to underestimate errors on column average (as well as the column average itself) in the vicinity of strong sources where relatively high methane concentrations are present close to the ground. Vertical smoothing errors will be generally overestimated as the prior uncertainty on methane exceeds its natural variability. However, the ESD computed in this way corresponds well to the RMS difference between individual IASI measurements and independent TCCON data (see below).

Issues relating to the sensitivity of the retrieval to vertical structure and smoothing errors can be addressed using the fine-scale averaging kernel:

$\mathbf{A}_{\mathrm{f}}=\mathbf{G K}_{\mathrm{f}}$.

The weighting function $\mathbf{K}_{\mathrm{f}}$ is distinguished from $\mathbf{K}$ in that derivatives may be computed with respect to perturbations on a finer grid than that used for the state vector. The averaging kernel for the layer average is $\mathbf{A}_{\mathrm{cf}}=\mathbf{M} \mathbf{A}_{\mathrm{f}}$.

The trace of the averaging kernel $\mathbf{A}$, evaluated using the weighting functions with respect to the retrieved state $(\mathbf{A}=$ GK), gives the degrees of freedom for signal (DOFS), which indicates the number of independent pieces of information which can be recovered from the retrieval.

Figure 1 shows averaging kernels for methane, typical of mid-latitude, for nadir-observing conditions. The surface temperature is assumed equal to the temperature of the lowest atmospheric layer. The panel on the left shows results assuming an NEBT at $280 \mathrm{~K}$ of $0.5 \mathrm{~K}$, while that on the right shows results for $0.1 \mathrm{~K}$ (commensurate with the actual IASI noise). Fitting close to this level is shown to be very important, adding 0.9 DOFS and increasing sensitivity to lowertropospheric methane.

The gain matrix can also be used to estimate the impact of errors not characterised in the measurement or prior covariance, e.g. given the covariance of errors in the temperature profile $\mathbf{S}_{T}$, the resulting covariance of errors in the retrieved state is

$\mathbf{S}_{x: T}=\mathbf{G K}_{T} \mathbf{S}_{T}\left(\mathbf{G K}_{T}\right)^{\mathrm{T}}$,

where $\mathbf{K}_{T}$ contains the derivatives of the FM with respect to temperature (defined on the same arbitrarily fine vertical grid as $\mathbf{S}_{T}$ ).

Figure 2 shows estimated error contributions to the retrieved methane profile and derived column averages (for the same assumptions as the right-hand panel in Fig. 1). The plot shows ESD, noise and smoothing errors. It also shows three estimates of temperature error, applying Eq. (11) to three different temperature error covariance matrices, each expressed on the model levels of the ECMWF analysis used: (i) "background", the ECMWF forecast background error covariance matrix from Collard (2007); (ii) "sampling", an estimate of the error associated with interpolating ECMWF temperature profiles to the times and locations of IASI soundings, determined in the same way as for water vapour (terms $\mathbf{S}_{\mathrm{d} t}+\mathbf{S}_{\mathrm{d} x}$ in Eq. 5); (iii) IASI, an error covariance matrix estimated for results from the (version 6) EUMETSAT operational IASI temperature retrieval. The plot shows the ESD for column-averaged mixing ratio to be $28 \mathrm{ppbv}$ and the error from modelling temperature to be of comparable magnitude. The temperature-related errors are relatively large compared 

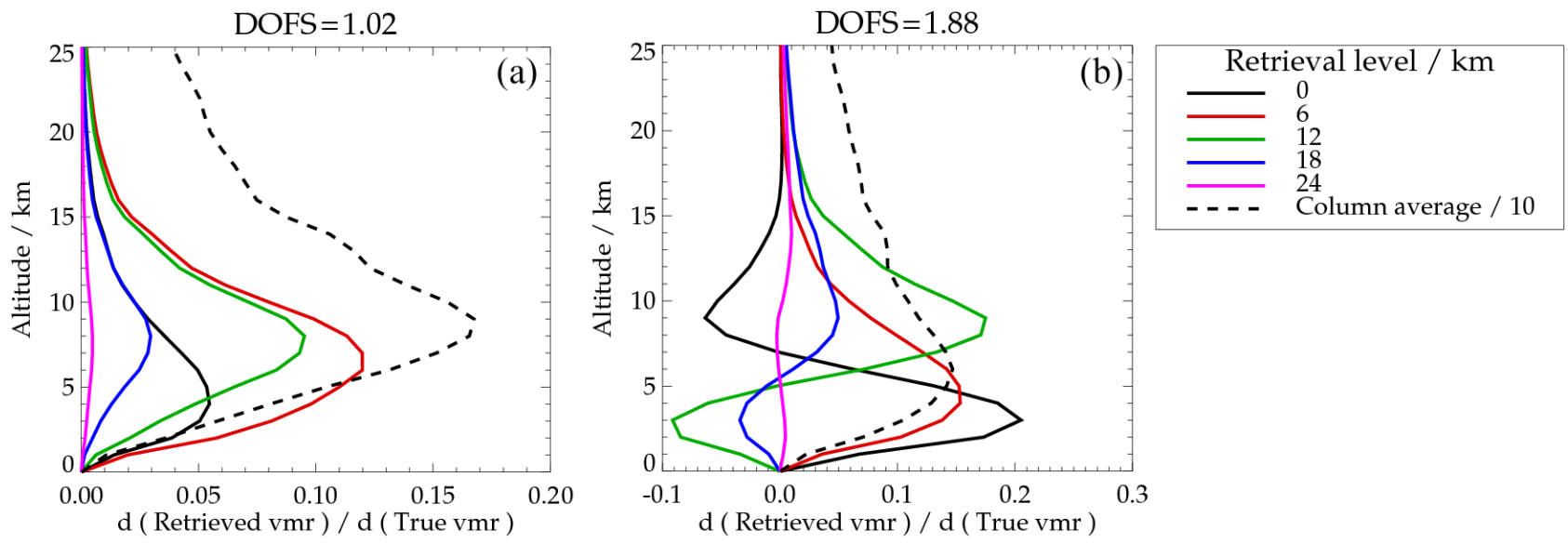

Figure 1. Averaging kernels for the methane profile at each retrieval level (solid) and for the column average (dashed). Panel (a) shows the result for NEBT $=0.5 \mathrm{~K}$, and panel (b) for NEBT $=0.1 \mathrm{~K}$. DOFS (the trace of the profile averaging kernel matrix) for each case is indicated above the panel. The averaging kernel for the column-averaged mixing ratio is also shown by the dashed line. This kernel is normalised so that it shows the derivative of the column-averaged mixing ratio with respect to perturbation in methane in fine layers, as a function of altitude (for an ideal retrieval this function should be 1, independent of altitude). Values of the column-averaged kernel shown here are divided by 10 to fit on the same scale as those for retrieval levels.

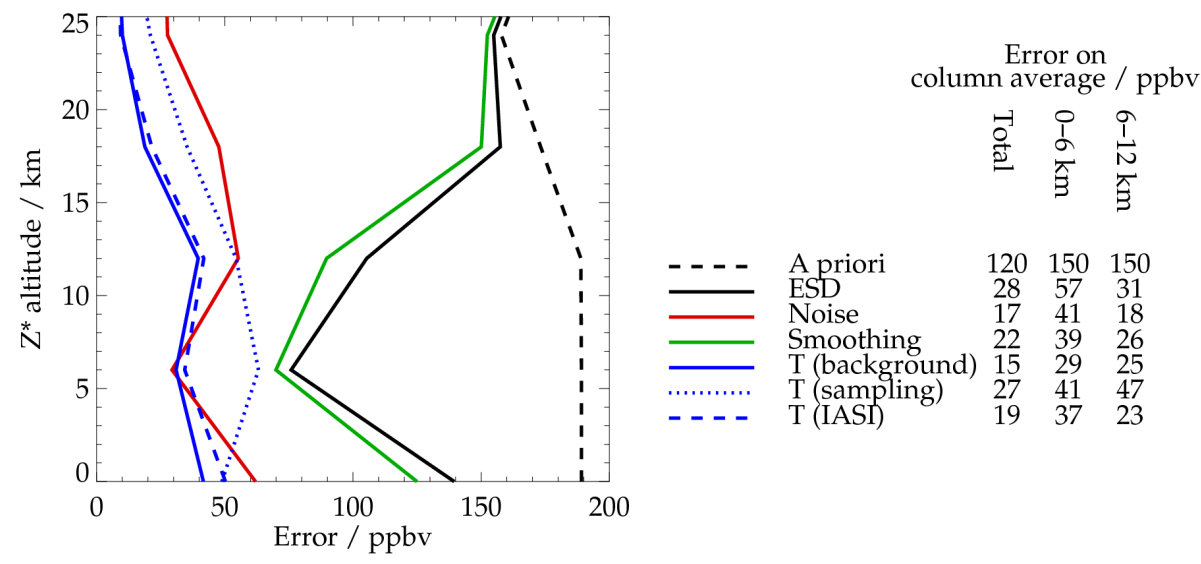

Figure 2. Estimated errors for the methane profile (in panel) and column average (indicated in caption).

to the natural variability of methane. The extent to which such errors are reduced by spatial and/or temporal averaging is determined by their spatial-temporal correlations, which are difficult to simply characterise. This paper focuses on $2.5^{\circ}$ (or coarser) latitude-longitude gridded, monthly mean IASI retrievals in expectation that the temperature-related errors on finer scales have a large random component which averages out. This is partly justified by (i) the level of agreement which is anyway found in comparisons to independent data (reported below); (ii) Simmons (2014), who reports errors in monthly mean ERA-Interim air temperatures to be considerably smaller than the background errors assumed here; and (iii) sampling errors being, by definition, negligible on scales coarser than the model grid. Temperature profiles retrieved from the same IASI soundings as the methane retrieval would, in several respects, be preferable to temper- ature fields from analyses or reanalyses, particularly when considering results at fine spatial-temporal scales; sampling errors no longer apply and, although errors would still exhibit spatial-temporal correlations (e.g. via common forward model error), their character would differ from those of the analyses/reanalyses ${ }^{5}$.

The sensitivity of the retrieval is dependent on meteorological conditions (particularly the surface-atmospheric temperature profile and thermal contrast between atmosphere and surface). This is reflected in the geographical and seasonal variation in the column-averaged and layer-averaged ESDs summarised, using retrieval results in 2009 and 2010, in Fig. 3. The ESDs in the column average and 0-6 km

\footnotetext{
${ }^{5}$ A pre-retrieval of temperature and humidity profiles and surface spectral emissivity is in development.
} 

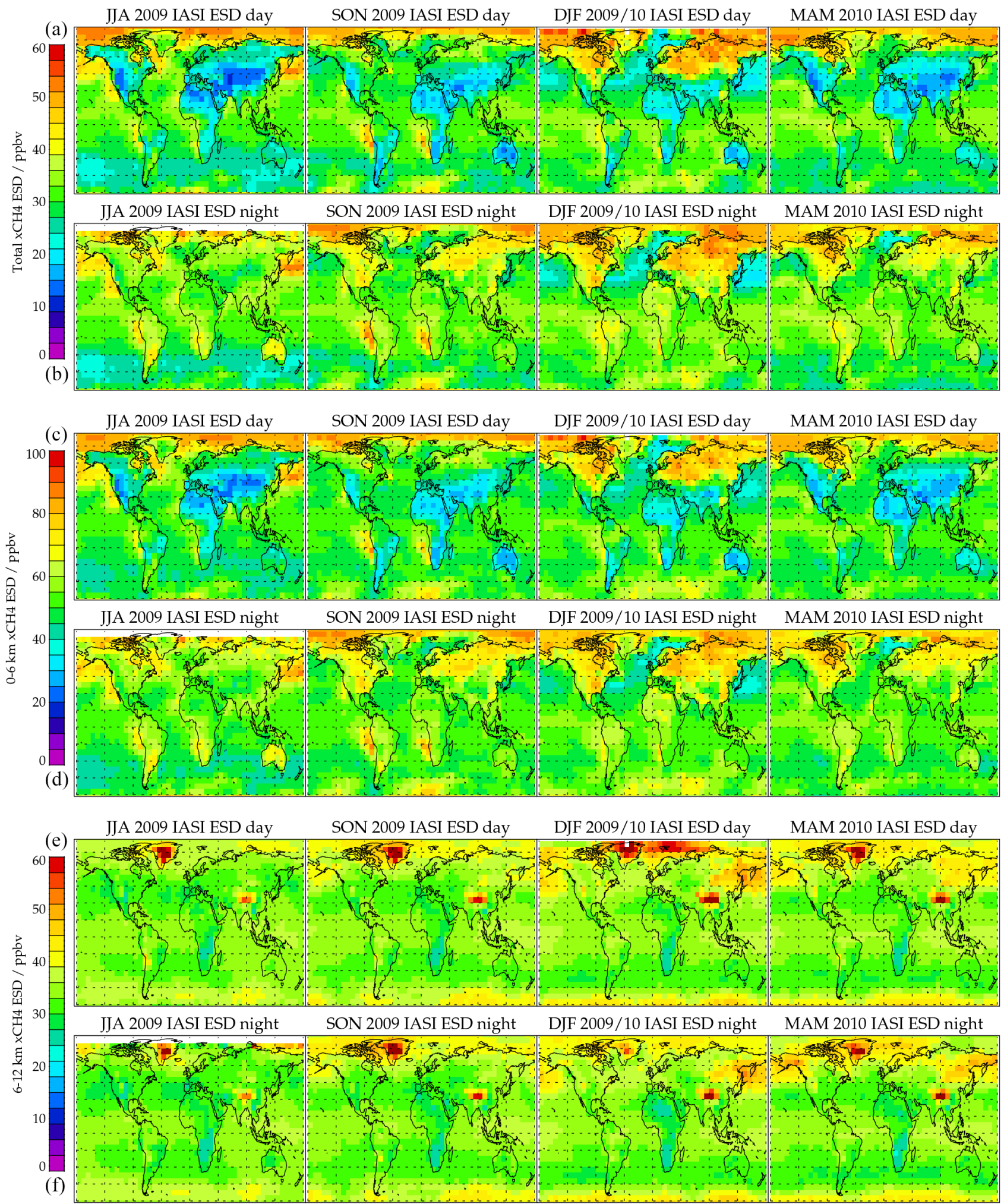

Figure 3. Average in $7.5^{\circ} \times 5^{\circ}$ latitude-longitude bins of the estimated SD (ESD) on column- and layer-averaged mixing ratio as a function of season (left to right) and for day (a, c and e) and night-time observing conditions (b, d and f). JJA is June, July and August 2009; SON is September, October and November 2009; DJF is December, January and February 2009/10; MAM is March, April and May 2010. Panels (a and b) show column-averaged ESD; panels (c-f) show the 0-6 and 6-12 km layer-averaged ESDs, respectively. 


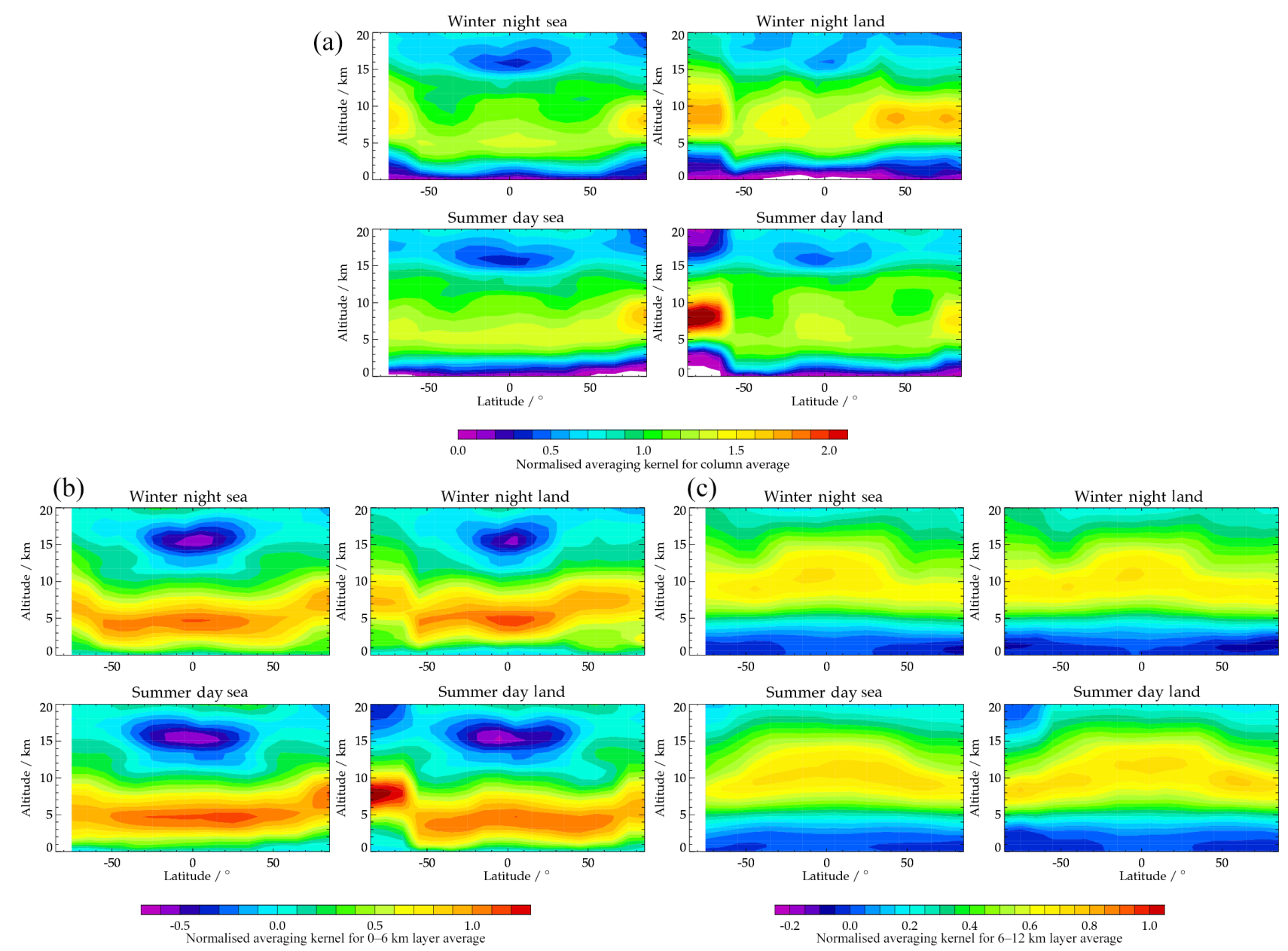

Figure 4. Averaging kernels for methane column average (a), 0-6 km layer average (b) and 6-12 km layer average (c), as a function of latitude and season, for observations over sea, daytime land and night-time land. Kernels are normalised as in Fig. 1.

layer average ${ }^{6}$ show similar distributions. They vary between day and night and also vary with season over land due to varying surface-air temperature contrast. Most precise retrievals occur over daytime land, except over particularly cold (frozen/snow/ice covered) surfaces in winter, where ESDs are larger than over sea at similar latitude. The ESDs in the $6-12 \mathrm{~km}$ layer average are large over Greenland and the Tibetan Plateau. Elsewhere, they are relatively low and uniform in comparison to ESDs in the 0-6 km layer. Figure 4 illustrates the variation of the averaging kernel for the column averaging mixing ratio. Averages from IASI retrievals performed in January and July 2009 are shown in $10^{\circ}$ latitude bands. In the figure, the two months are presented as winter and summer conditions, with data for summer conditions taken from the January zonal mean in the Southern Hemisphere and the July mean in the north (vice versa for the winter). Diurnal variations in surface temperature and

\footnotetext{
${ }^{6}$ Layers are defined in terms of $z^{*}$ pressure-altitude levels; $0 \mathrm{~km}$ is the surface. Hence, $0-6 \mathrm{~km}$ means surface to $422 \mathrm{hPa} ; 6-12 \mathrm{~km}$ means $422-178 \mathrm{hPa}$.
}

air-ground thermal contrast cause the sensitivity of methane retrievals over land to differ between daytime (descending node, 09:30 local solar time) and night-time (ascending node, 21:30) observations. Methane retrievals over land generally show greater near-surface sensitivity in daytime than nighttime. Due to thermal inertia of the ocean, methane retrieval performance is more uniform with respect to latitude, season and time of day than it is over land. In summer, daytime sensitivity is greater over land than sea; however, the situation is reversed in the winter at mid-latitudes (when the sea is typically warmer than the land). The kernels for 0-6 and 6-12 km layer averages show clearly that two pieces of information, broadly corresponding to those layers, are available in the tropics and mid-latitudes under most conditions, though with variable sensitivity near to the surface. Towards the poles, height-resolved information is much reduced; the kernels for the two layers tend to converge (both peaking above $5 \mathrm{~km}$ ).

The methane retrieval scheme is influenced by the specified $\mathrm{N}_{2} \mathrm{O}$ distribution. Simulations for cloud-free conditions show that over a realistic range of $\mathrm{N}_{2} \mathrm{O}$ perturbations, the 

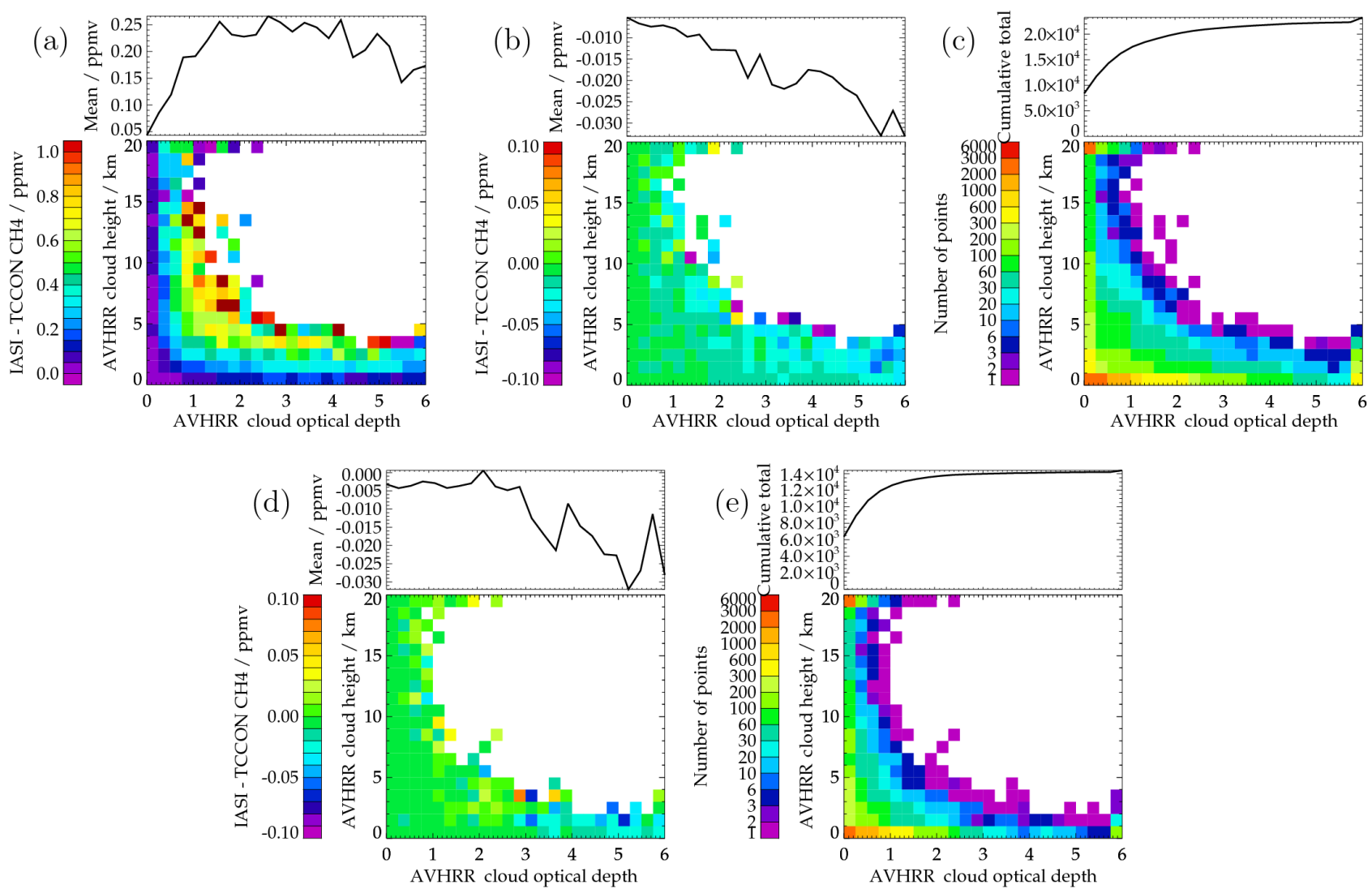

Figure 5. Panel (a) shows the mean differences between IASI and TCCON measurements (in 2009) as a function of the AVHRR cloud optical depth and height for the retrieval in which $\mathrm{N}_{2} \mathrm{O}$ is fitted and cloud neglected. The line plot above shows the mean difference over all cloud heights, as a function of optical depth. Panel (b) shows the same but for the new scheme with $\mathrm{N}_{2} \mathrm{O}$ defined and cloud parameters retrieved (note the change in ranges shown). Panel (c) shows the number of IASI retrievals in each bin, with the sub-panel above showing the cumulative total number of points as a function of increasing optical depth. Panels (d) and (e) are the same as panels (b) and (c), respectively, after removing scenes with retrieved cloud fraction larger than 0.2 .

methane retrieval responds linearly, such that a $1 \%$ heightindependent scaling of the $\mathrm{N}_{2} \mathrm{O}$ profile gives rise to a similar magnitude error in retrieved column-averaged methane. This arises because the co-retrieved cloud parameters accommodate the spectral signature of the $\mathrm{N}_{2} \mathrm{O}$ error, and the retrieved methane profile then accommodates the impact of the erroneous cloud parameters on the methane spectral features. Although the retrieval scheme specifies a fixed tropospheric value of $\mathrm{N}_{2} \mathrm{O}$, the NOAA flask record indicates there is a meridional gradient from the most southerly to northerly sites of order $\pm 0.5 \%$ (IPCC, 2013). This would be expected to give rise to similar systematic errors in methane ( $\pm 10 \mathrm{ppbv})$. Given the simple response of the retrieval to perturbing the assumed $\mathrm{N}_{2} \mathrm{O}$, it is possible to correct retrieved column-averaged methane post hoc, given a better estimation of the $\mathrm{N}_{2} \mathrm{O}$ height-resolved distribution than that assumed in the retrieval (e.g. from a model), although such corrections have not been carried out in the analysis reported here.

\section{Performance in the presence of cloud}

The performance of the retrieval scheme in the presence of cloud depends on the ability of the two cloud parameters included in the fit to accommodate the real effects of cloud vertical and horizontal structure. The potential of the approach was initially demonstrated via retrieval simulations in which cloud optical properties and 3-D structure on finer scales than the IASI field of view was explicitly represented in synthesising measured spectra (Kerridge, 2012). In this paper, the impact of cloud on methane retrievals is confirmed using real IASI flight data. Differences between column-averaged methane retrieved from IASI and those from the TCCON (see Sect. 5.4) are examined as a function of cloud height and optical depth ${ }^{7}$. For this purpose, effective cloud optical

\footnotetext{
${ }^{7}$ In principle, we should account here for the IASI vertical sensitivity by using averaging kernels, as is done in the more detailed TCCON comparisons reported in Sect. 5 below. However, this would not significantly affect the findings reported in this section. As illustrated in Fig. 13, the impact of accounting for vertical sensitivity
} 
depth and height for each IASI measurement were estimated by applying the Optimal Retrieval of Aerosol and Cloud (ORAC) scheme (Poulsen, 2012) to co-located visible-nearIR and thermal-IR images observed by AVHRR/3 on board MetOp. The ORAC scheme was applied to AVHRR/3 radiances averaged over each IASI field of view (given in the IASI Level 1 (L1) files) to give an effective ${ }^{8}$ optical depth and cloud height, together with phase and effective radius. Thick, high cloud is excluded from this analysis by the preselection of IASI measurements based on the BT difference test described earlier. All IASI retrievals within $100 \mathrm{~km}$ and $1 \mathrm{~h}$ of all available TCCON measurements in 2009 were selected. The difference between all these IASI retrievals and the associated TCCON measurements were averaged into bins of the AVHRR/3-derived cloud optical depth and height (without attempting to correct for differences in vertical sensitivity). Results are summarised in Fig. 5 for both our original scheme $\left(\mathrm{N}_{2} \mathrm{O}\right.$ retrieved, cloud neglected) and the current scheme $\left(\mathrm{N}_{2} \mathrm{O}\right.$ specified, cloud parameters fitted). Cloud leads to a strong positive bias in the methane retrieved by the original scheme. Figure 5 shows that, even though independent, co-located AVHRR/3-derived cloud information is potentially available ${ }^{9}$, the sensitivity of the original scheme to residual cloud is such that a very stringent filter would have to be applied to avoid significant error in IASI-retrieved column-averaged methane. In practice, this would result in the vast majority of scenes having to be excluded. However, the scheme which co-retrieves two cloud parameters is shown to be much less sensitive to residual cloud: for cloud effective heights below $5 \mathrm{~km}$, the methane retrieval has a bias of less than $30 \mathrm{ppbv}$. For cloud effective optical depth below 1 , it is insensitive to cloud at all heights. The errors with respect to TCCON tend to be negative, especially for low altitude cloud of effective optical depth $>3$. As evident from the figure, co-retrieved cloud fraction (from the methane retrieval scheme) can be used in post-screening to remove methane retrievals which are likely to be biased, such that the vast majority of screened retrievals have a bias smaller than 5 ppbv. Results presented in the evaluation section below are based on using retrievals with an effective cloud fraction $<0.2$.

(on average $10 \mathrm{ppbv}$ ) is small compared to the magnitude of the cloud-related errors considered in this section.

${ }^{8}$ Effective in the sense that cloud is assumed to be horizontally homogenous across the IASI field of view and is represented by a geometrically thin single layer of either liquid or ice particles.

${ }^{9}$ Cloud retrieval from the ORAC scheme is available only during daytime.

\section{Evaluation of the retrievals}

\subsection{Overview}

In this section we present comparisons of the height-resolved IASI retrievals with independent sources. Ideally, retrievals would be validated by comparing to accurate, co-located, measured profiles of methane which sample spatial and temporal variability as extensively as IASI and with comparable or finer resolution. Given such information, retrieved column- and layer-averaged methane mixing ratios could be compared to the corresponding independent data both directly and also accounting for the influences of the prior and vertical sensitivity of the IASI retrieval using averaging kernels as follows:

$c_{\mathrm{txI}}=c_{a}+\mathbf{A}_{\mathrm{t}}\left(\boldsymbol{x}_{\mathrm{t}}-\boldsymbol{a}_{\mathrm{t}}\right)$,

where $c_{a}$ is the column average computed from the a priori profile; $\mathbf{A}_{\mathrm{t}}$ is the averaging kernel matrix for the layer, computed from the retrieval gain matrix and spectral weighting function matrix evaluated on the (finely resolved) vertical grid of the independent data; $\boldsymbol{x}_{\mathrm{t}}$ is the independently measured mixing ratio profile; and $\boldsymbol{a}_{\mathrm{t}}$ is the a priori profile interpolated to the vertical grid of the independent data. There are, however, no directly measured datasets which provide sufficient spatial and temporal coverage to enable validation of the IASI retrievals globally over the duration of its mission. We therefore compare the following four sources of correlative data which each have complementary attributes:

- The MACC-II GHG flux inversion reanalysis (Bergamaschi, 2013) provides global 3-D methane fields which span the period of our IASI methane retrievals. It employs the TM5-4DVar flux inversion system driven by meteorology from ECMWF's ERA-Interim reanalysis. Daily average methane distributions are provided at a horizontal resolution of $6^{\circ}$ longitude by $4^{\circ}$ latitude. Here we focus on the reanalysis dataset ("v10S1NOAA_ra") which spans 2000-2012 and is based on the assimilation of NOAA surface level flask measurements. Although the reanalysis does not provide an unambiguous validation dataset (being based on assimilation of data into a model), it remains valuable to compare to IASI because (1) the reanalysis has been validated against independent observations (see Bergamaschi, 2013) and also found to compare very well with the GOSAT measurements also used here (Parker, 2015); and (2) it provides complete global profile information such that comparisons with IASI columnand layer-averaged mixing ratios can properly take into account vertical sensitivity (using Eq. 12) and be performed consistently over the full globe and most of the IASI mission duration. The dataset is particularly valuable for testing that the retrievals realistically represent differences in the spatial and seasonal behaviour of the 
upper- and lower-tropospheric layer averages (an aspect not well covered by measurements due to limited sampling). MACC GHG data are also used here to enable retrieval sensitivity to be accounted for in comparisons with other datasets, as described below.

- Aircraft in situ measurements of methane profiles from HIAPER Pole-to-Pole Observations (HIPPO) which provide accurate measured methane profiles to compare with vertically resolved satellite retrievals, e.g. see Wecht (2012) and Alvaredo (2015). The main limitation of this dataset is its spatial and temporal sampling: HIPPO executed five campaigns, each consisting of numerous individual flights, sampling over the US and Pacific between January 2009 and September 2011 (Wofsy, 2012). Methane profiles were measured in situ as the aircraft executed a series of ascent/descent manoeuvres. Most profiles sampled only the middle-lower troposphere, though on occasion the manoeuvres extended into the upper troposphere. In order to make comparisons to column averages and layer averages, and to apply averaging kernels, we extend the HIPPO profiles by filling upwards with temporally and spatially interpolated profiles from the MACC-II GHG reanalysis.

- The TCCON of ground-based FTSs (Wunch, 2011) provides the most comprehensive set of ground-based column-averaged methane measurements against which to validate satellite retrievals. Although TCCON does not provide height-resolved information, comparisons to it are particularly valuable for testing the temporal stability of the IASI retrievals seasonally and over the full mission.

- GOSAT column-averaged methane retrievals produced by the University of Leicester (Parker, 2015) from the GOSAT SWIR spectrometer, using the so-called " $\mathrm{CO}_{2}$ proxy" technique ${ }^{10}$. Version 6 data, as produced for the ESA Greenhouse Gas CCI project (Buchwitz, 2015), are used here. These comparisons generally support the findings from the MACC column-averaged comparisons. They are also included here so that users who might consider joint assimilation of the two satellite datasets are aware of the level of consistency between them.

Retrieved and independent data are co-located and their differences binned in latitude and longitude for a given month

\footnotetext{
${ }^{10}$ In this approach, the ratio of $\mathrm{CH}_{4}$ to $\mathrm{CO}_{2}$ column-averaged mixing ratios is retrieved from a spectral interval around $1.6 \mathrm{mi}-$ crons containing both methane and $\mathrm{CO}_{2}$ bands. The $\mathrm{CH}_{4}: \mathrm{CO}_{2}$ ratio is multiplied by the $\mathrm{CO}_{2}$ column average from a model. The approach exploits the fact that $\mathrm{CO}_{2}$ deviations from uniform mixing are much smaller than those of methane and allows errors in instrument characterisation and radiative transfer modelling to largely cancel out.
}

or season (details of the binning are given in the individual sections below). In the comparisons reported here, IASI retrievals which have co-retrieved cloud fraction $>0.2$ or unusually high fit cost are excluded from the analysis.

In all cases we compare column averages. Where the independent data allow (MACC and HIPPO), we also compare separately lower- and upper-tropospheric layeraveraged methane from surface to $z^{*}=6 \mathrm{~km}$ and between $z^{*}=6$ and $12 \mathrm{~km}$. In each case, comparisons are made both directly and taking into account retrieval sensitivity using the averaging kernels. Where the independent data are height resolved, this is done by applying Eq. (12). In the case of GOSAT and TCCON (which only provide column information) this cannot be done, so instead we estimate the (smoothing) error in the IASI column average using the co-located MACC profile, given by the difference $\left(c_{\mathrm{M}}-c_{\mathrm{MxI}}\right)$, where $c_{\mathrm{M}}$ is the directly computed MACC layer average and $c_{\mathrm{MxI}}$ is the result of Eq. (12) applied to the MACC profile. The smoothing error $\left(c_{\mathrm{M}}-c_{\mathrm{MxG}}\right)$ of the GOSAT-TCCON profile can be similarly estimated, using the corresponding GOSATTCCON kernels and prior profiles. We then estimate what GOSAT-TCCON would be expected to observe, given the IASI measurement, accounting for the respective smoothing errors ${ }^{11}$ :

$$
\begin{aligned}
c_{\mathrm{I}: \mathrm{G}} & =c_{\mathrm{I}}+\left(c_{\mathrm{M}}-c_{\mathrm{MxI}}\right)-\left(c_{\mathrm{M}}-c_{\mathrm{MxG}}\right) \\
& =c_{\mathrm{I}}+c_{\mathrm{MxG}}-c_{\mathrm{MxI}} .
\end{aligned}
$$

Assuming that the MACC profiles are sufficiently accurate that the binned mean difference $c_{\mathrm{MxG}}-c_{\mathrm{MxI}}$ is accurate then differences between binned mean values of $c_{\mathrm{I}: \mathrm{G}}$ and the corresponding result based on the retrieved GOSAT-TCCON column $\left(c_{\mathrm{G}}\right)$ should reveal systematic errors in one or another retrieval rather than differences which might be expected based on their different vertical sensitivity.

\subsection{Comparison to MACC-II GHG flux inversion reanalysis}

Comparisons with IASI are made by interpolating MACC-II GHG data for a given day to the geographical locations of individual IASI observations and averaging both into $2.5^{\circ} \times$ $2.5^{\circ}$ longitude-latitude bins for individual months. Columnaveraged methane and layer averages between pressure levels corresponding to $z^{*}=6$ and $12 \mathrm{~km}$ are considered.

Figure 6 shows seasonal mean distributions of the column averages from IASI and MACC-II GHG based on data processed between June 2009 and May 2010 and averaged into $7.5^{\circ} \times 5^{\circ}$ longitude-latitude bins over 3-month intervals ${ }^{12}$.

\footnotetext{
${ }^{11}$ Because the sensitivity of GOSAT (and TCCON) varies relatively little with height compared to IASI, there is very little difference in practice between results using $c_{\mathrm{MxG}}$ in this equation or the uncorrected MACC-II GHG column average, $c_{\mathrm{M}}$.

${ }^{12}$ This grid size is chosen to be appropriate for the comparisons to GOSAT as discussed in the following section.
} 


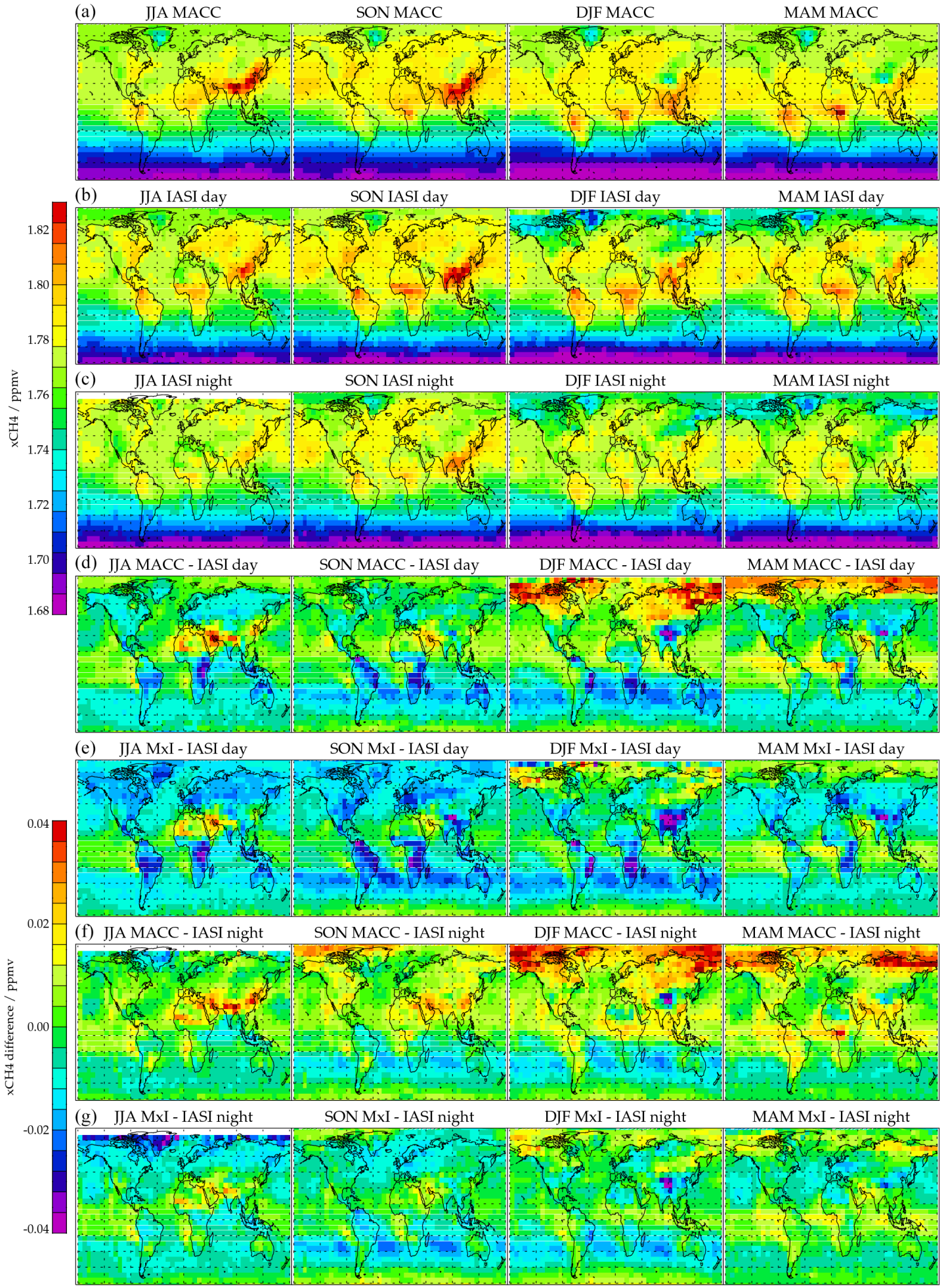

Figure 6. Comparisons of IASI and MACC-II GHG column-averaged mixing ratio. Each column of the figure shows results for a different season; JJA is June, July and August 2009; SON is September, October and November 2009; DJF is December, January and February 2009/10; MAM is March, April and May 2010. Panels (a-c) show, respectively, results from MACC-II GHG, IASI daytime retrievals and IASI night-time retrievals. Panels (d-g) show differences between MACC-II GHG and IASI, separately for day and night, with and without applying the IASI averaging kernels. MxI is used in the panel titles as shorthand for "MACC-II GHG after applying IASI averaging kernels". 


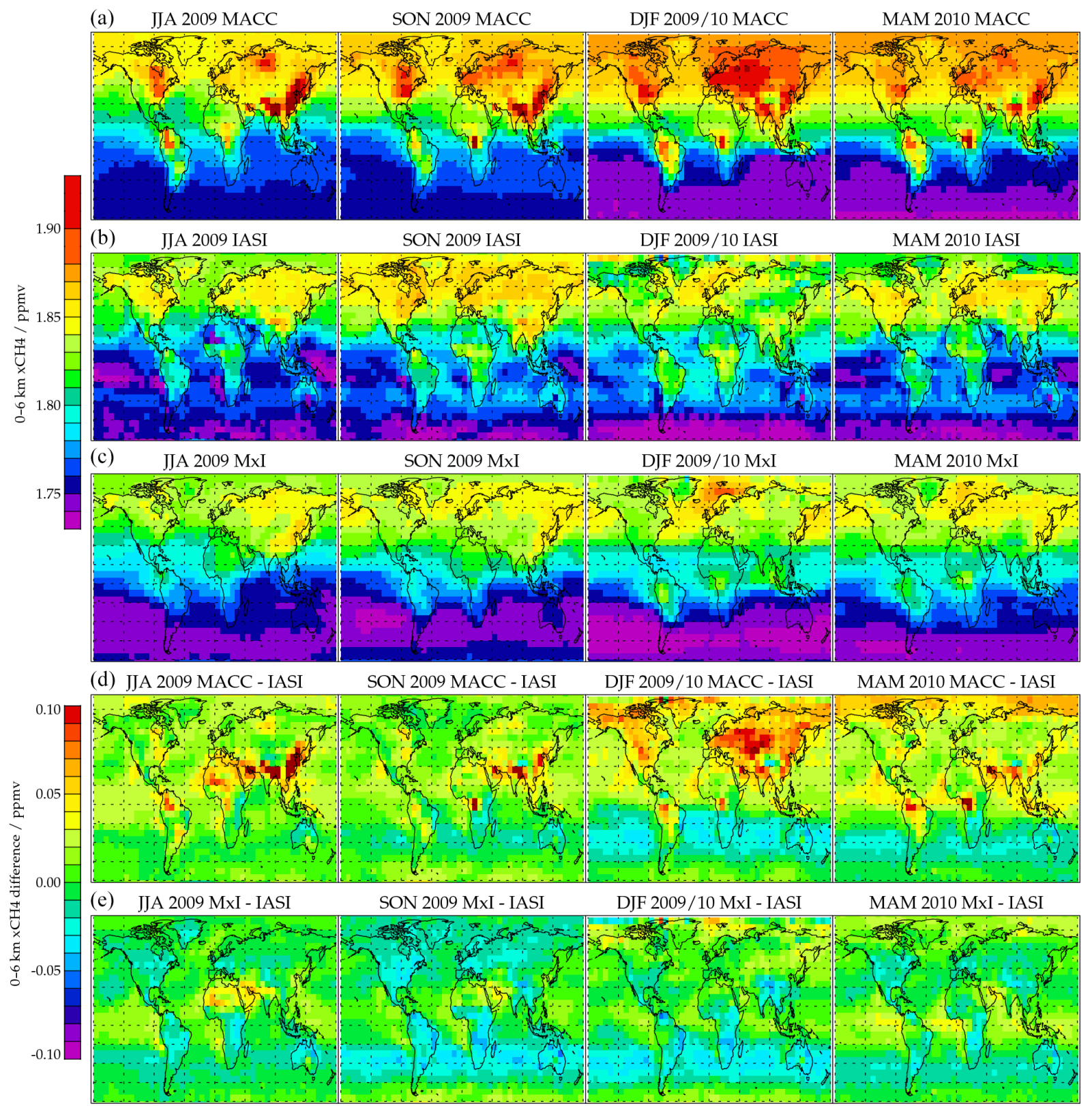

Figure 7. Comparisons of IASI and MACC-II GHG 0-6 km $\left(z^{*}\right)$ layer-averaged mixing ratio. Daytime only results shown. Panels (a-c) show, respectively, results from MACC-II GHG, IASI and MACC-II GHG with the IASI averaging kernels applied (MxI). Panels (d, e) show differences between MACC and IASI directly and after applying the IASI averaging kernels.

IASI and MACC-II GHG exhibit broadly similar spatial distributions (e.g. north-south gradient) and seasonal variations (in particular features associated with emissions in southern Asia). IASI daytime observations over land show generally larger values than MACC-II GHG, particularly over regions associated with surface emissions. In the direct comparison (MACC-II GHG - IASI), differences are seen to be comparatively large at high northern latitudes. These differences are much reduced in comparisons after the averaging kernels are applied (labelled "MxI - IASI" in the figure), indicat- ing prior influence on the retrieval accounts for most of the discrepancy. IASI tends to be biased low at high northern latitudes because the a priori tropospheric mixing ratio is biased low at these latitudes and, due to low surface temperature, IASI spectra are less sensitive to methane variations than they are at lower latitudes. Such discrepancies are less apparent at high southern latitudes where the a priori tropospheric mixing ratio is in reasonable agreement with MACCII GHG. Use of the averaging kernels also reduces differences between MACC-II GHG and IASI over source regions 


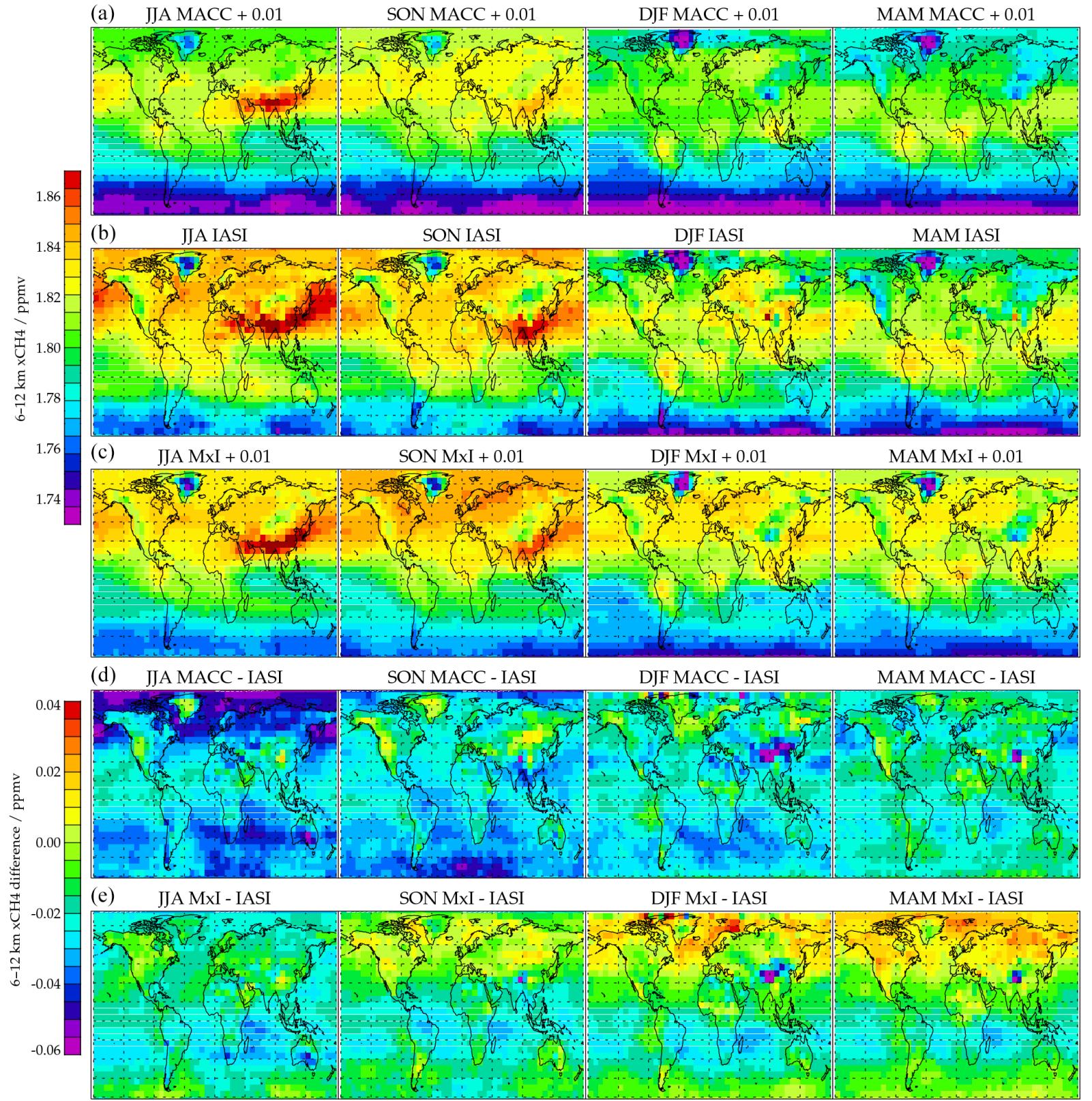

Figure 8. Comparisons of IASI and MACC-II GHG 6-12 km $\left(z^{*}\right)$ layer-averaged mixing ratio. Daytime only results shown. Panels (a-c) show, respectively, results from MACC-II GHG, IASI and MACC-II GHG with the IASI averaging kernels applied (MxI). MACC and MxI results have $0.01 \mathrm{ppmv}$ added, as indicated in the plot title. Panels (d, e) show differences between MACC and IASI directly and after applying the IASI averaging kernels (without any offset applied to MACC or MxI).

in Asia. However, IASI is lower than MACC-II GHG (by up to $40 \mathrm{ppbv}$ ) over Arabia/Iran and the Sahara. It is also consistently lower (by 10-20 ppbv) over some regions of the tropical oceans, especially in March-May. In contrast, from September to February it is consistently higher in southern mid-latitudes by $\sim 20 \mathrm{ppbv}$. This could be partly explained by a low bias of MACC-II GHG against TCCON in the Southern Hemisphere reported in Alexe (2015). In comparisons to TCCON and GOSAT, IASI is found to be biased high (see Sects. 5.3 and 5.4), though by a considerably smaller amount.

There are regions over the tropical oceans in which IASI is lower than MACC-II GHG by $\sim 20$ ppbv, especially in March-May. Similar patterns appear also in IASI-GOSAT comparisons. A low bias in IASI data could plausibly be explained by persistent low cloud cover (see Sect. 4 above); however, the geographical pattern of the bias is not fully consistent with this explanation (a similar bias is not present in 

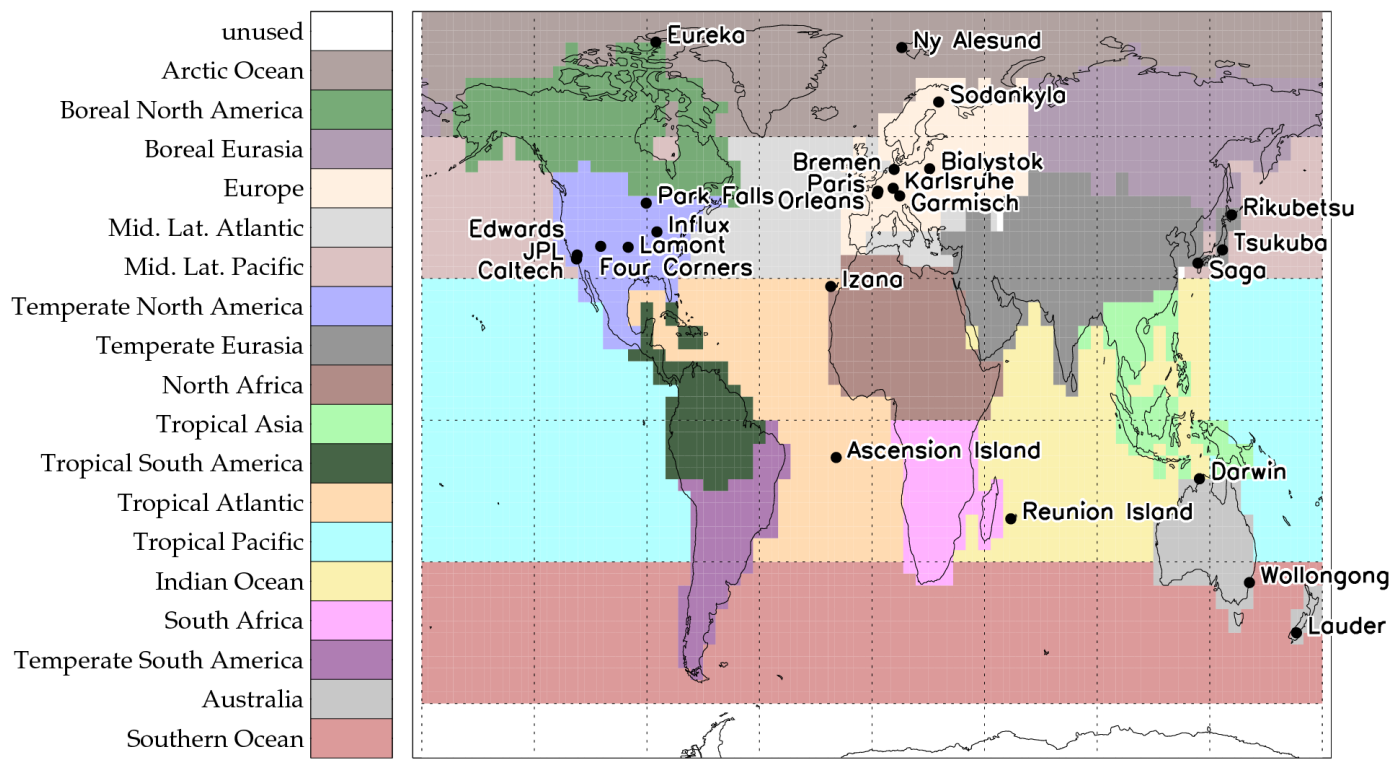

Figure 9. The regions used for comparisons with MACC and the locations of TCCON sites.

other regions of known persistent low cloud cover). The bias could also be explained by the presence of slightly higher than expected tropospheric $\mathrm{N}_{2} \mathrm{O}$ mixing ratio in these areas, which might be supported by HIPPO observations (Kort, 2011).

Figures 7 and 8 compare the $0-6$ and $6-12 \mathrm{~km}$ layer averages from IASI with MACC-II GHG. The IASI global distributions are seen to capture well methane source regions (e.g. South-East Asia, Amazon, central Africa) which feature prominently in the MACC-II GHG distribution, although the amplitudes of such regional enhancements retrieved by IASI are lower than MACC-II GHG, consistent with mixing ratios in source regions being highest nearest to the surface where IASI sensitivity is lowest. After applying IASI averaging kernels to MACC-II GHG, however, agreement is much improved, with differences comparable to those found for column-averaged mixing ratios. IASI observes the Australian methane source to be larger than MACC-II GHG, which could perhaps explain why methane values in Southern Hemisphere mid-latitudes are generally higher for IASI than for MACC-II GHG, particularly in summer. Methane distributions in the 6-12 km layer are markedly different to those in the 0-6 km layer for both IASI and MACC-II GHG. The pattern of land surface sources is reflected only weakly and the asymmetry between Northern and Southern hemispheres is markedly reduced. The most prominent feature in Northern Hemisphere summer and autumn is seen to be outflow from the South-East Asian monsoon, which is captured quite consistently by IASI and MACC-II GHG. In direct comparisons, MACC values are generally $10-20 \mathrm{ppbv}$ lower than IASI. When averaging kernels are applied, which capture the influence on the retrieved 6-12 km layer average from the atmosphere both above and below, agreement is generally improved. However, a discrepancy is then revealed at high northern latitude, particularly in spring when MACCII GHG values are $\sim 20$ ppbv larger than IASI values. These differences must be related to differences in representing the stratospheric vertical profile and its contribution to the 6$12 \mathrm{~km}$ layer average in either IASI or MACC-II GHG ${ }^{13}$.

The evolution in time of these comparisons has been studied by averaging the monthly-binned IASI and MACC values from $2.5^{\circ} \times 2.5^{\circ}$ latitude-longitude intervals into the regions illustrated in Fig. 9. Over land, these regions correspond to those used in the TRANSCOM model intercomparison exercise (from Fraser, 2013, based on Gurney, 2002). Time series of the column averages in these regions are shown in Fig. 10. Each panel compares IASI with MACC-II GHG (direct and after applying the averaging kernels). The caption in each panel gives the correlation coefficient $(r)$, mean difference $(m)$ and SD of the differences $(s)$ between IASI and MACC-II GHG. Panels are organised in order of average latitude from north to south. IASI and MACC-II GHG clearly agree well on the secular trend in methane over the 8-year period of 2007-2015, and seasonal cycles also agree well. As noted previously, averaging kernels have most impact at high northern latitudes, significantly increasing correlation coefficients in that case. After applying the averaging kernels, correlation coefficients are all $\geq 0.85$. Mean differences are $\leq 10 \mathrm{ppbv}$ except in southern mid-latitudes, where IASI values are $\sim 20 \mathrm{ppbv}$ higher than MACC-II GHG. SDs of the monthly, regional mean values are typically $\sim 3 \mathrm{ppbv}$ (al-

\footnotetext{
${ }^{13}$ For MACC-II GHG, stratospheric 3-D structure is that specified by TM5 whereas, for IASI, it is an annual average zonal-mean cross section from TOMCAT, from which there will be systematic, seasonally dependent departures.
} 

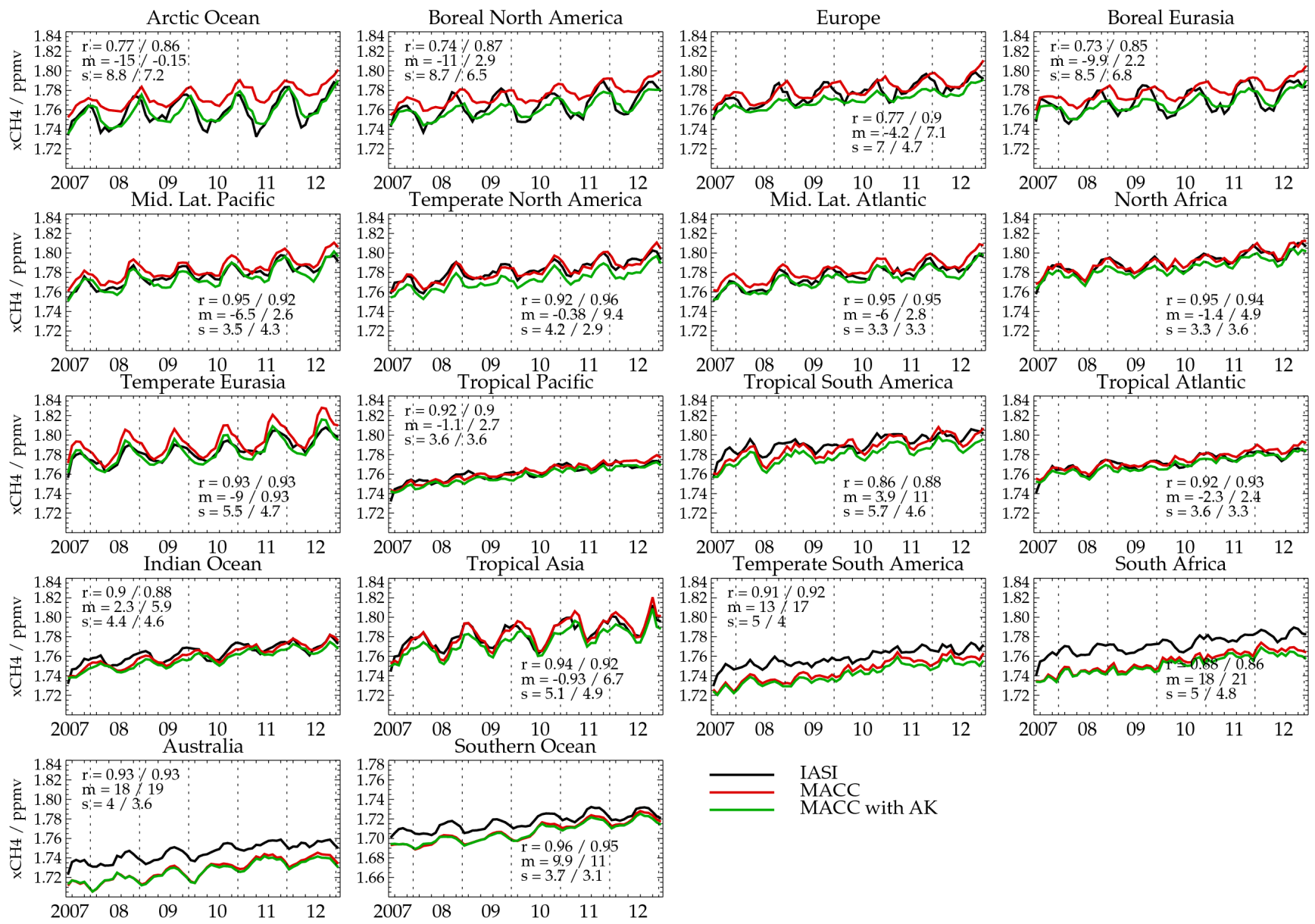

Figure 10. Time series of monthly, regionally averaged column-averaged methane from IASI and MACC. IASI measurements are shown in black; values directly from MACC are in red; MACC results after applying the IASI averaging kernel (AK) are shown in green. The caption in each panel indicates the correlation between IASI and MACC $(r)$, the mean difference IASI-MACC $(m)$ in ppbv and the SD in the difference $(s)$ in ppbv. Two values are given in each case, first for the direct IASI-MACC comparison and then after applying the kernels. Dashed vertical lines mark the beginning and end of each year.

though these are somewhat larger at high northern latitudes). This is an order of magnitude lower than the typical ESD of $\sim 30 \mathrm{ppbv}$ for an individual IASI sounding, but large in comparison to the standard error in the mean (since many thousands of individual IASI soundings contribute to each monthly regional mean).

Figures 11 and 12 show the corresponding time series for the $0-6$ and $6-12 \mathrm{~km} z^{*}$ layer averages. In the $0-6 \mathrm{~km}$ layer, the impact of vertical sensitivity is more pronounced, with IASI typically underestimating the true layer average, particularly at high northern latitudes and also in temperate Eurasia and other land regions where near-surface methane concentrations are particularly high. Much of these discrepancies are explained by the averaging kernels, leaving correlations between 0.7 (boreal Eurasia, where IASI sees more pronounces seasonal variations) and 0.94 (temperate North America/mid-latitudinal Atlantic). In many locations, the seasonal patterns at $6-12 \mathrm{~km}$ are quite different from those of the total and $0-6 \mathrm{~km}$ layer average. In particular, tropical regions have relatively weak seasonal cycles in this upper layer and this is captured by IASI in accordance with MACC-II GHG. In temperate Eurasia (affected strongly by the monsoon outflow) and mid-latitude Pacific, the opposite is true (stronger seasonal cycle in upper layer). In the North Atlantic, there is a pronounced phase shift in the seasonal cycle exhibited by the two layers, consistently seen in IASI and MACC (with or without kernels). These differences in seasonal cycles, together with the level of consistency between IASI and MACC, support the assertion that IASI is providing vertically resolved information. As with the column average, correlation coefficients are $\sim 0.9$ after applying averaging kernels. The Arctic region shows the largest differences, with a quite distinct seasonal cycle evident in IASI compared to MACC (whether or not averaging kernels are applied). Throughout the tropics and southern latitudes, IASI tends to be 10-20 ppbv higher than MACC (after apply- 

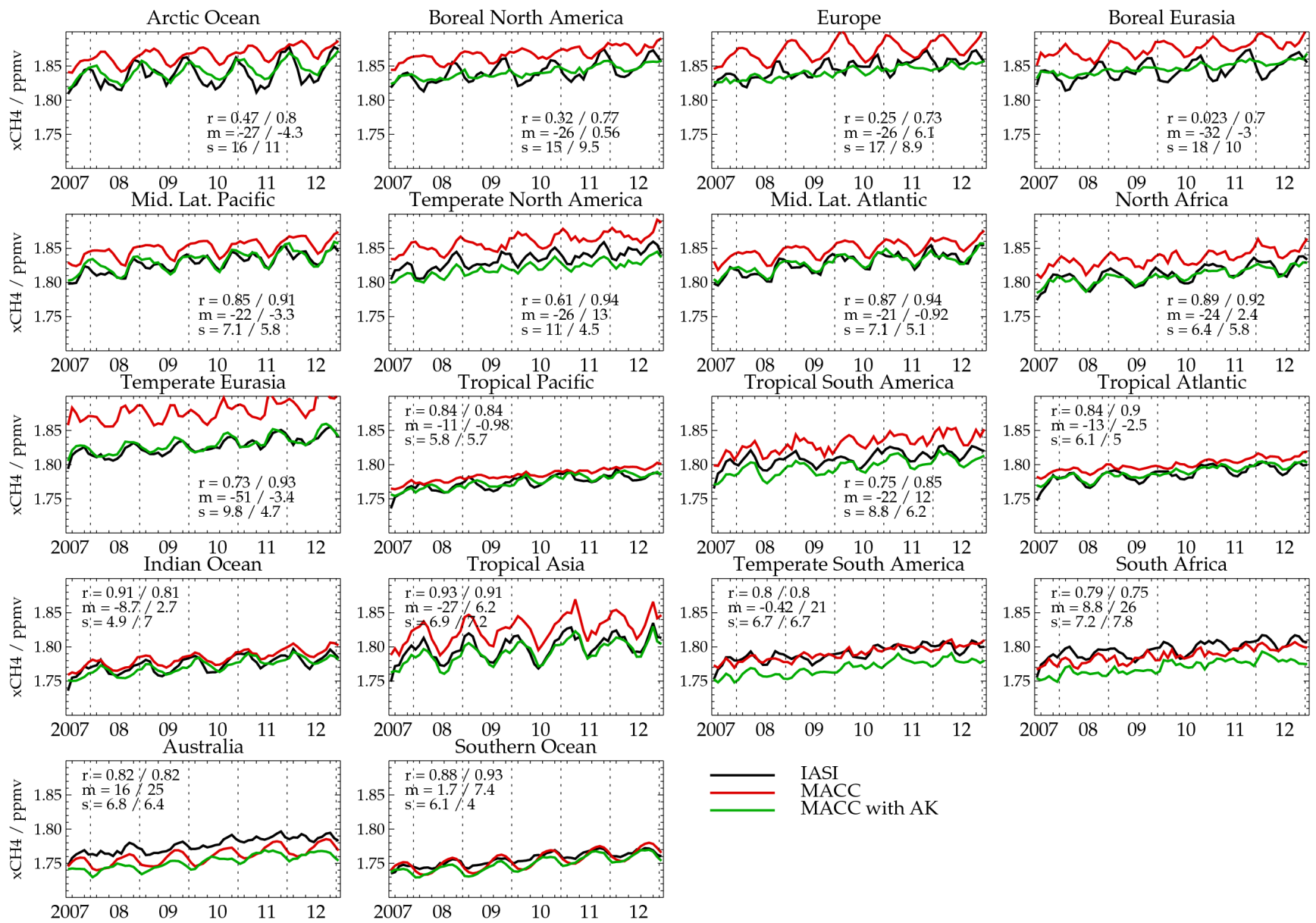

Figure 11. As previous figure but for $0-6 \mathrm{~km}$ layer-averaged methane.

ing averaging kernels) in the upper layer. Biases in the lower layer are typically much smaller, except over Australia.

\subsection{Comparisons to GOSAT retrievals}

The approach described in Sect. 5.2 for MACC-II GHG is adapted here to account for the sparse spatial sampling of GOSAT, especially over the ocean where retrievals only exist in sun-glint geometry. The starting point is to obtain $2.5^{\circ} \times$ $2.5^{\circ}$ longitude-latitude daily binned fields from GOSAT and IASI (daytime only retrievals); monthly mean fields are then accumulated from these daily files. In the IASI case, geographical sampling for each given day is restricted to only those grid cells for which GOSAT data also exist. The resulting monthly means are then further averaged to $7.5^{\circ} \times 5^{\circ}$ longitude-latitude resolution over 3 -month intervals. A $7.5^{\circ}$ longitude resolution was chosen to be just sufficient to eliminate gaps that would otherwise appear between GOSAT orbit tracks in the resulting plots. The number of GOSAT or IASI retrievals in each of these bins is sufficiently large that the estimated random error on the mean value (based on the estimated error on individual retrievals) is well below $1 \mathrm{ppbv}$.
According to Parker (2015), GOSAT retrievals have a bias (vs. TCCON) of around 4.8 ppbv.

Results are illustrated in Fig. 13. Differences in direct comparisons between GOSAT and IASI are seen to be broadly similar to those found between MACC-II GHG and IASI (Fig. 6), which is consistent with the agreement found between the same GOSAT and MACC-II GHG datasets in Parker (2015). Adjusting for the different vertical sensitivities of IASI and GOSAT (using MACC-II GHG) is seen to account for most of the systematic difference between the two at high northern latitudes in winter and spring. The IASI values adjusted for vertical sensitivity are seen to be lower by 10-20 ppbv over Arabia, North Africa and over tropical oceans. At southern mid-latitudes IASI is higher (by $\sim 10 \mathrm{ppbv}$ ) than GOSAT. This bias is about a factor of 2 smaller than that also seen in this region in the comparison to MACC-II GHG (from September to February), implying that MACC-II GHG is negatively biased with respect to both IASI and GOSAT in this region. 

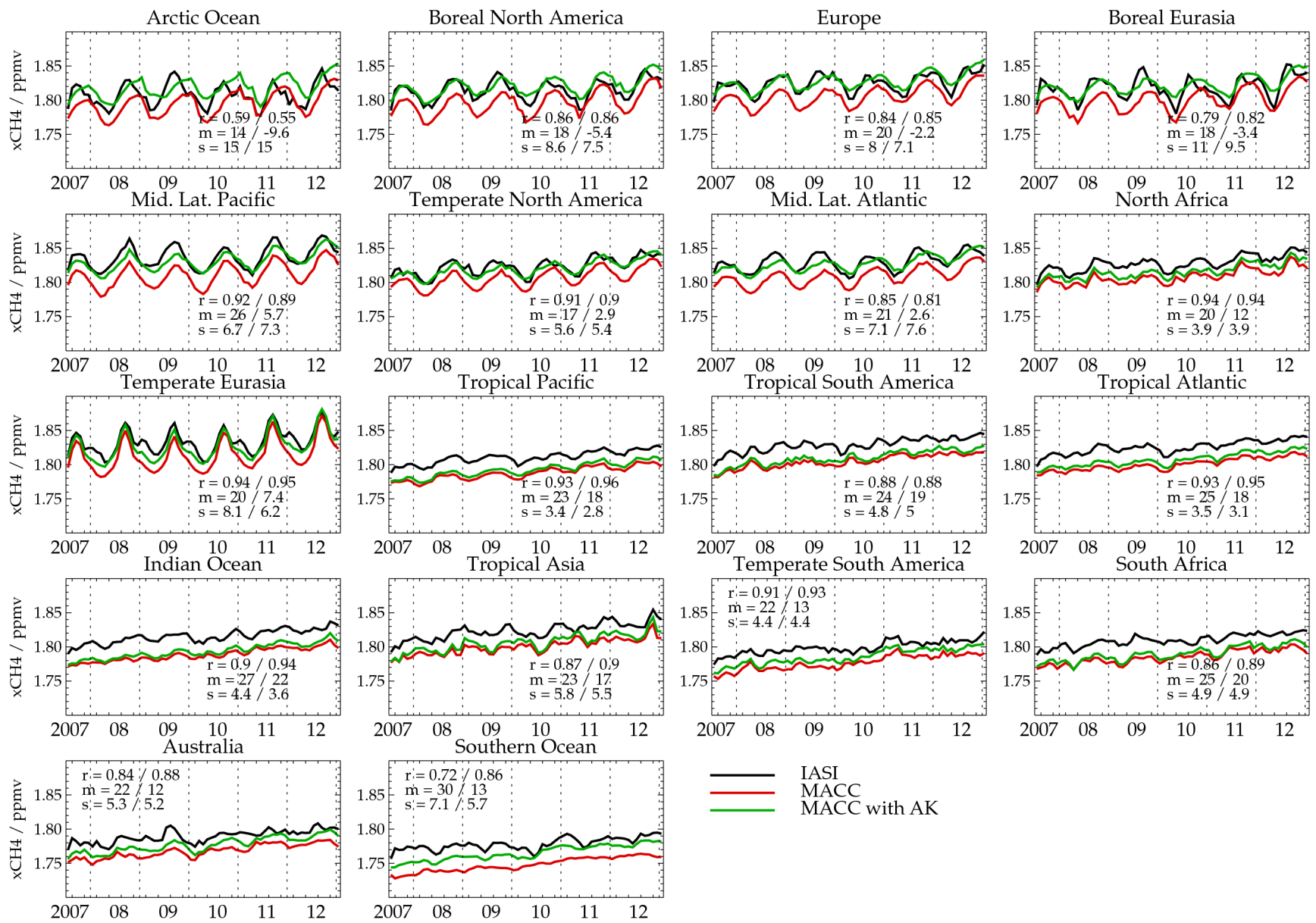

Figure 12. As previous figure but for 6-12 km layer-averaged methane.

\subsection{Comparison to TCCON}

Here we compare IASI to all available TCCON data from version "GGG2014". This includes data from the following sites: Armstrong Flight Research Center, Edwards (Iraci, 2014a), Ascension Island (Feist, 2014), Białystok (Deutscher, 2014), Bremen (Notholt, 2014), California Institute of Technology (Wennberg, 2014c), Darwin (Griffith, 2014a), Eureka (Strong, 2014), Four Corners (Dubey, 2014b), Garmisch (Sussmann, 2014), Indianapolis (Iraci, 2014b), Izana (Blumenstock, 2014), Jet Propulsion Laboratory (Wennberg, 2014a, e), Karlsruhe (Hase, 2014), Lamont (Wennberg, 2014d), Lauder (Sherlock, 2014a, b), Manaus (Dubey, 2014a), Orleans (Warneke, 2014), Paris (Te, 2014), Park Falls (Wennberg, 2014b), Réunion Island (De Maziere, 2014), Rikubetsu (Morino, 2014b), Saga (Shiomi, 2014), Sodankylä (Kivi, 2014), Tsukuba (Morino, 2014a) and Wollongong (Griffith, 2014b). For some stations, additional temporal coverage was given in the earlier GGG2012 release, and we exploit this here, using GGG2012 in periods when this is available but GGG2014 is not. Data for Ny-Ålesund were taken from the 2012 release. Locations of the TCCON stations used are indicated in Fig. 9.

IASI column-average data within $200 \mathrm{~km}$ of each TCCON station are averaged over a month for the days on which there are TCCON observations. Monthly averages are presented if there are at least 100 IASI individual observations and 10 TCCON observations contributing to each mean. Typically there are several thousand IASI observations contributing to each monthly mean, for which a standard error in the mean of $\leq 1 \mathrm{ppbv}$ would be expected from typical ESDs on individual retrieved column averages.

Since TCCON does not provide profile information, we cannot directly account for the effect of the IASI vertical sensitivity but do so indirectly using MACC-II GHG as a transfer standard, as described in Sect. 5.1. In order to extend this correction beyond the end of 2012, we use the MACCII GHG delayed mode analysis ("v10_an"), which is available from 2013 until mid-2014. This assimilates GOSAT retrievals (from the RemoTec proxy scheme of Schepers, 2012), in addition to the NOAA surface flask observations.

Time series of comparisons to TCCON stations are shown in Fig. 14. In the absence of any TCCON measurements in 

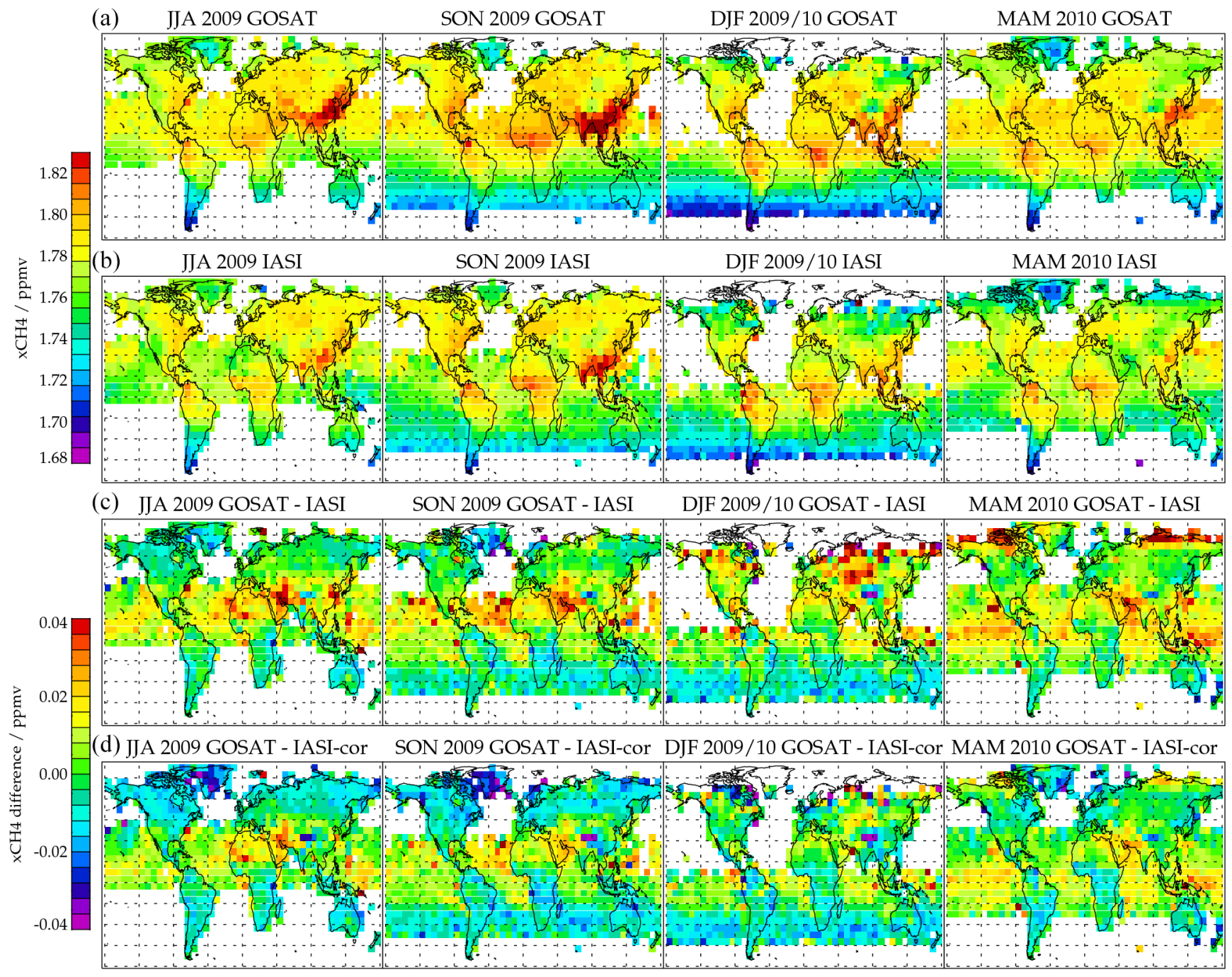

Figure 13. Seasonal mean distributions of column-averaged methane in 2009-2010 from GOSAT (a) and IASI daytime observations, sampled on a daily basis like GOSAT (b). Panel (c) shows differences between the GOSAT and the IASI daytime means. Panel (d) shows differences after correcting IASI for differences in the IASI/GOSAT vertical sensitivity using MACC.

a month, the IASI time series is completed using the IASI monthly mean considering all days in the month (these points are shown for context/continuity in the plots but do not contribute to any derived statistics). As indicated in the panel headings, results from some stations (seen to sample broadly similar methane variations) are grouped together to make the time series in each panel more complete and to enable results to be presented in a more compact form.

The caption in each panel gives the correlation coefficient $(r)$, mean difference $(m)$ and SD of individual TCCON-IASI differences $(s)$; two values are given for each quantity (separated by a slash), corresponding to the direct comparison of TCCON to IASI and the comparison to IASI after adjusting for vertical sensitivity (via MACC-II GHG profiles). Correlation coefficients before correction are 0.76-0.91 and generally improve after the adjustment. Correlation is only 0.65
( 0.73 after correction) at Izana. Some of this degradation may be related to the high altitude of the station $(2300 \mathrm{~m})$ and/or its specific location (on Tenerife), which is subject to peculiar localised meteorological conditions and is in an area often affected by desert dust.

As might be expected, the correction generally raises the IASI values (as the tropospheric prior value is usually systematically low). The correction tends to have more impact in the north, although agreement with TCCON is not always improved. The correction usually reduces the SD in the difference between IASI and TCCON. After correction, the mean difference and SD are $\leq 10 \mathrm{ppbv}$ in most cases, with the notable exception of the Four Corners site. Here IASI captures the seasonal cycle well but underestimates TCCON by $\sim 25 \mathrm{ppbv}$, even after correction. This anomaly is presumably explained by the fact that the Four Corners TCCON site 

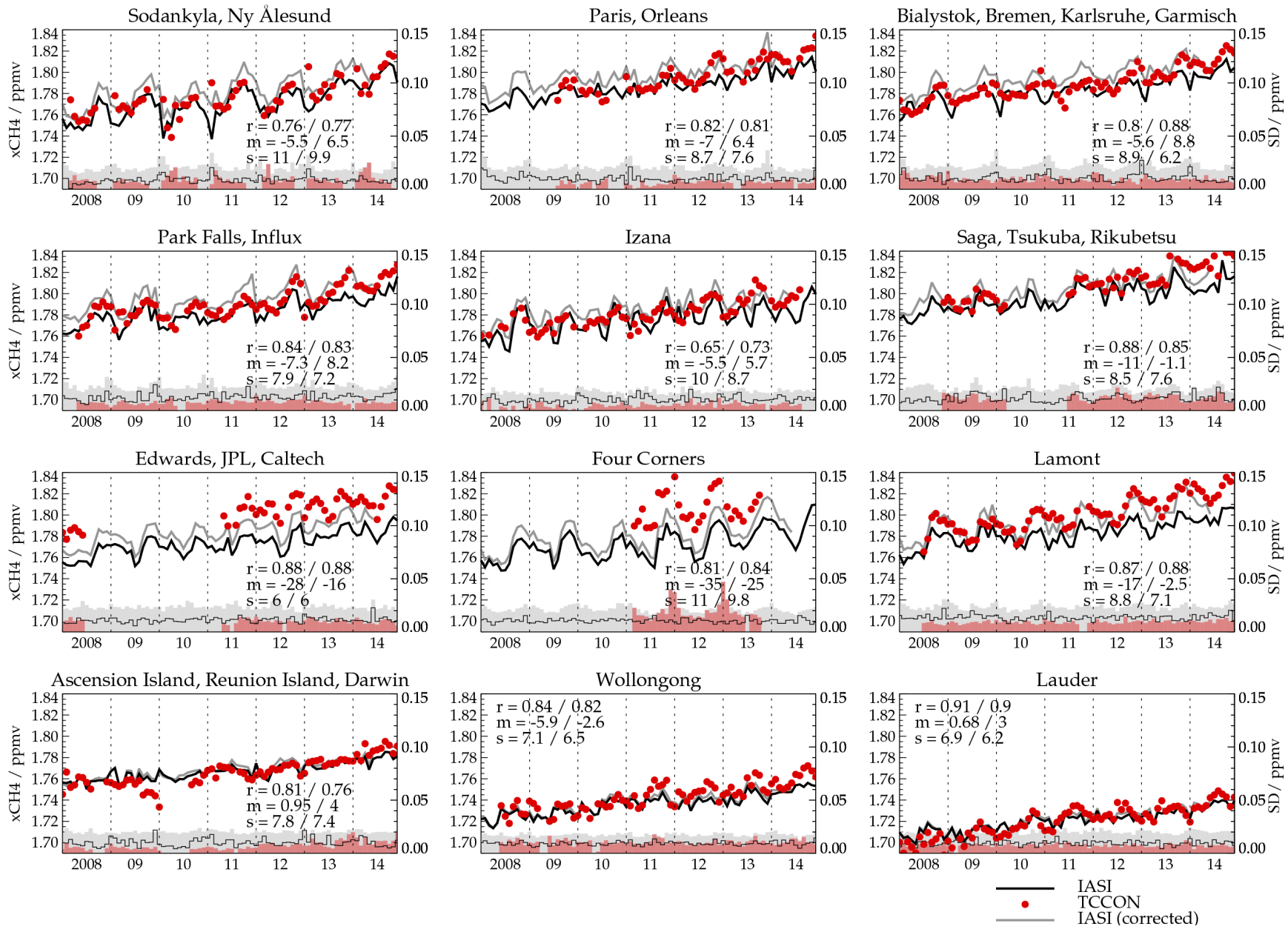

Figure 14. Comparison of IASI and TCCON monthly column-averaged methane mixing ratio from 2008 to 2014 . The black line shows IASI and red points show TCCON. The grey line shows the IASI result corrected to account for the IASI smoothing error using MACC (see text). Histograms indicate the SD in the IASI and TCCON monthly mean (refer to right-hand axis). Figures in the caption indicate the correlation coefficient $(r)$, mean difference ( $m$, in ppbv) and SD in the difference ( $s$, in ppbv). Two values are given for each quantity (separated by a slash), corresponding to the black (IASI direct) and grey (IASI corrected) curves, respectively.

is located close to an extremely strong methane source associated with coal mining and related activities (Kort, 2014), and so it samples localised methane variability represented neither by IASI data sampled over a circular region of radius $200 \mathrm{~km}$ nor by the MACC-II GHG data used in the adjustment.

Each panel in Fig. 14 also shows (as histograms along the $x$ axis, referring to the right-hand $y$ axis) the SDs of IASI and TCCON data in monthly bins. Grey bars show the SDs of all individual IASI retrievals in each monthly bin. These are generally higher than those for TCCON (shown in light red), reflecting the significant contribution of random errors to individual IASI retrievals. These SDs are comparable to the ESD of individual retrievals, as computed by the optimal estimation retrieval scheme (illustrated in Fig. 3). The histogram indicated by the thin black line, shows for each given month the SD of the set of the daily mean IASI val- ues. Each daily mean is the average of all IASI observations within $200 \mathrm{~km}$ of the TCCON site. This quantity generally agrees rather well with the TCCON SD, reflecting the dayto-day variation of methane within each month as seen by the two sensors. Again, the exception here is Four Corners, where TCCON has a higher SD than IASI, supporting the hypothesis that this station samples methane variability which is substantial on a local scale.

Figure 15 summarises the TCCON comparisons for 2013 in a compact form, showing the individual monthly samples from TCCON and IASI as individual points, colour-coded by the site (or grouping of sites). Four Corners is excluded from this plot because of the sampling issue identified above. Error bars show the SDs of daily mean values in each monthly bin. The top-left panel plots TCCON against the retrieval prior, whose variation arises from meridional structure in the annual mean stratospheric distribution. The absence of 

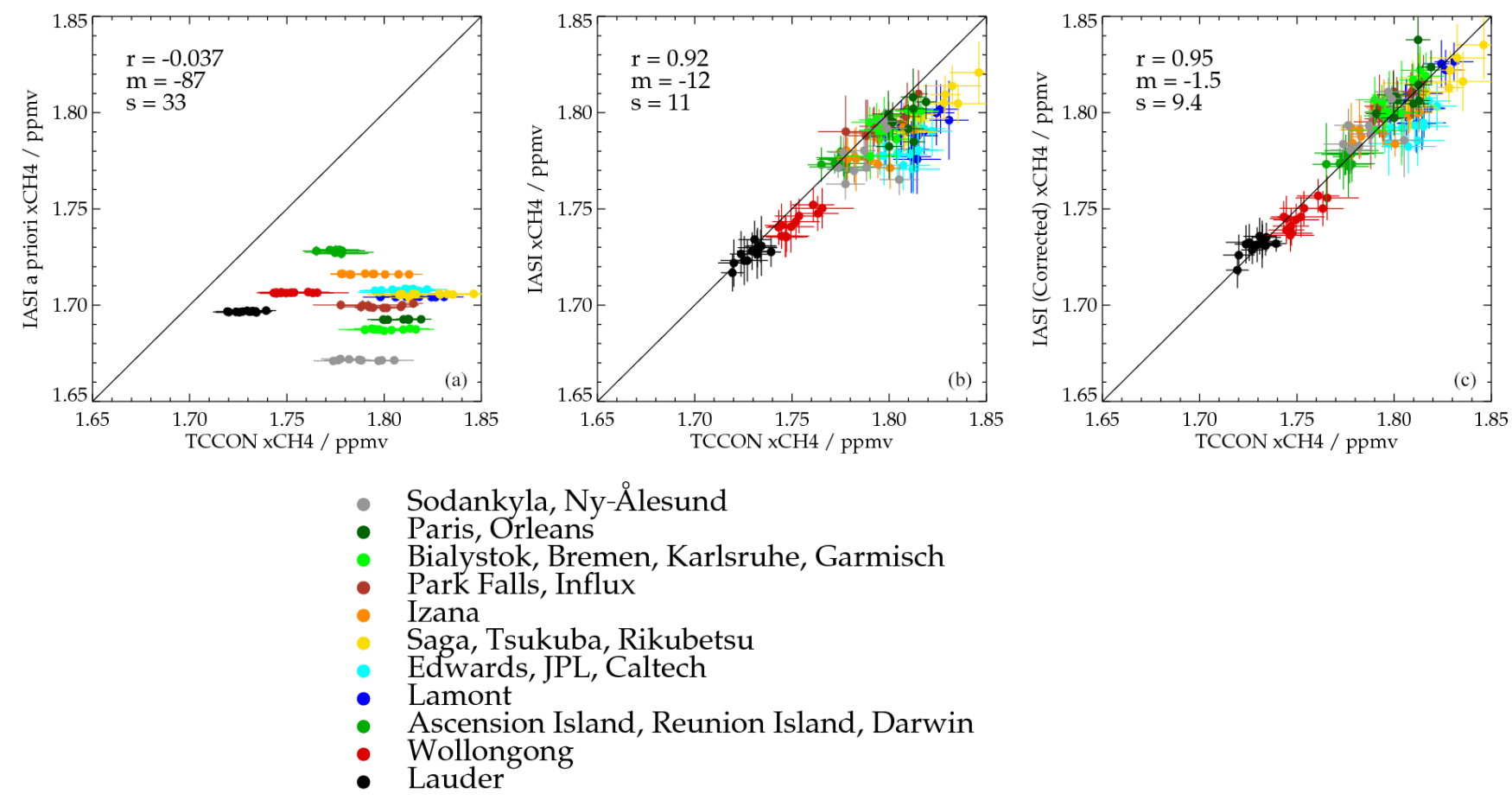

Figure 15. Scatter plots comparing TCCON and IASI column-averaged methane mixing ratio in 2013. Each point compares the mean values for each month, with different colours indicating different (groups of) TCCON stations as in the caption. Error bars show the SDs in daily mean values within each month. Panels show (from a to c): IASI a priori vs. TCCON; IASI vs. TCCON; IASI after correction for smoothing error using MACC.

any discernible correlation between prior and TCCON values clearly demonstrates that agreement between the retrieval and TCCON to be wholly dependent upon information provided by the IASI measurements. It also illustrates why IASI retrievals tend to be biased low at high northern latitudes, where measurement sensitivity is lowest and the prior contribution is therefore most influential. The top centre panel shows the direct IASI-TCCON scatter, which indicates a correlation coefficient of 0.92 and that IASI is systematically lower by $\sim 11 \mathrm{ppbv}$. The top right panel shows the scatter between TCCON and the adjusted IASI retrieval, in which the correlation coefficient is increased to 0.95 and the negative IASI bias is reduced to $\sim 1.5 \mathrm{ppbv}$. The SD in the monthly IASI-TCCON differences is $\sim 10 \mathrm{ppbv}$.

\subsection{Comparison to HIPPO airborne observations}

We co-locate IASI and HIPPO data by selecting, for each HIPPO profile, all IASI observations within $200 \mathrm{~km}$ and $6 \mathrm{~h}$ (taking the mean latitude, longitude and time of the aircraft measurement). We then compare each HIPPO profile to the mean of the associated IASI observations. We also compute the SD of individual IASI soundings. The number of IASI samples in each mean profile is variable (typically in the range 1-20) due to cloud occurrence and latitude (more samples are found at high latitude where IASI's $2200 \mathrm{~km}$ swaths overlap). Figure 16 shows the comparison for HIPPO cam- paign 5, which is particularly interesting for our purposes as variations in the upper- and lower-tropospheric layers (represented here by $0-6$ and $6-12 \mathrm{~km}$ layer averages) are quite distinct. These differences are very poorly captured by the IASI prior but relatively well captured by the retrieval; illustrating that IASI can effectively resolve two independent layers centred in the lower and upper troposphere. There is a particularly pronounced meridional structure in the 6-12 km layer between profile index $30-40$, which is captured by IASI and clearly present in both HIPPO and the part of the field which has been infilled with MACC-II GHG data.

Figure 17 summarises (in a similar format analogous to figures of Alvaredo, 2015) the level of agreement between IASI and HIPPO, binning into $10^{\circ}$ latitude intervals, the differences between the individual IASI and HIPPO matches, considering all five campaigns. The figure shows the mean difference (HIPPO-IASI) in each bin (with and without applying IASI averaging kernels), together with the SD about the mean of the differences between the individual IASI profiles and the HIPPO profile associated to them. Each HIPPO profile is only used once in accumulating the statistics: SDs are computed first for all IASI profiles which match individual HIPPO profiles, then these are accumulated over all HIPPO profiles in a given latitude bin. For comparison, the mean ESD of the IASI observations is also shown. The number of samples in each bin is typical several hundred, so the 


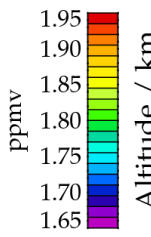

(b)

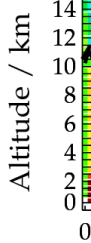

HIPPO CH4 (filled)

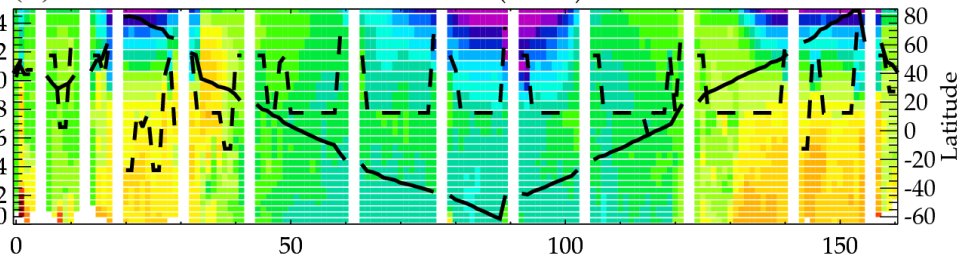

(a)

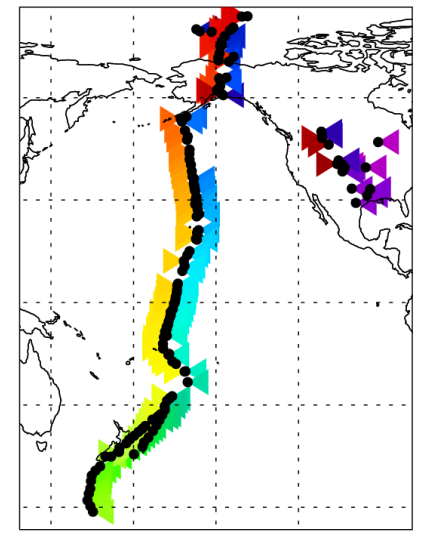

(c)

Total column average vmr

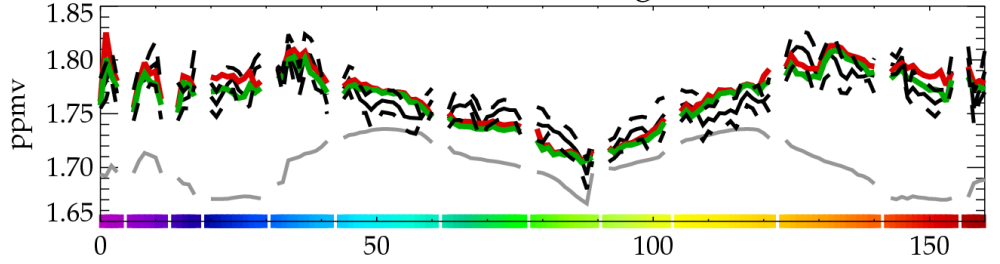

(d)

$0-6 \mathrm{~km}$ layer average $\mathrm{vmr}$

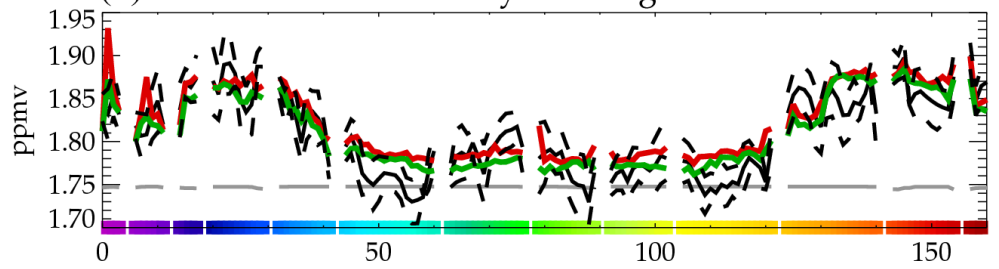

(e) $\quad 6-12 \mathrm{~km}$ layer average vmr

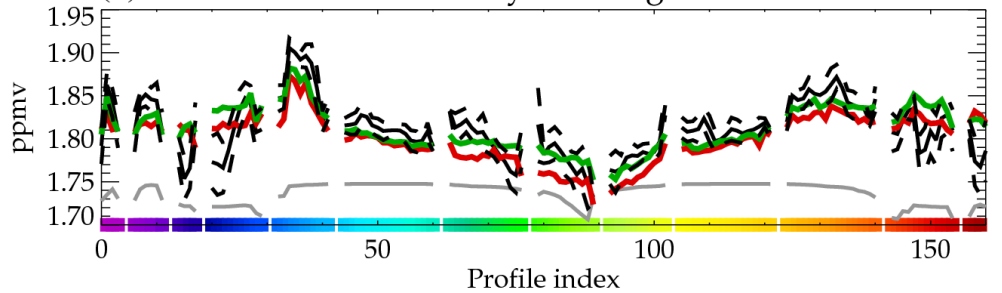

Figure 16. Comparison of IASI and HIPPO for flight campaign 5 (between 9 August and 9 September 2011). Panel (a) shows the flight track. Actual measurement locations are indicated with black dots; associated coloured triangles indicate the profile index, as shown on the $x$ axis of panels on the right (b-e) (colours under the axis correspond to colours used in the map). Panel (b) shows the cross section as measured by HIPPO, after binning and filling (upwards) using the MACC GHG reanalysis. The solid black line in this plot shows the latitude of each profile (refer to $y$ axis on the right); the dashed black line shows the maximum $\left(z^{*}\right)$ altitude of the HIPPO measurement, above which profiles are filled with MACC. Gaps (filled with white) between the coloured regions divide data from different flights (on different days). Panels (c-e) compare IASI and HIPPO column- and layer-averaged mixing ratios. The mean of matched IASI retrievals is shown in black. The dashed lines show the mean \pm SD of the matched retrievals. Grey shows the IASI a priori; red shows the HIPPO result; green shows HIPPO after applying the IASI averaging kernel.

standard error in the mean value is almost always $<1 \mathrm{ppbv}$ (whether estimated from the predicted retrieval error or the $\mathrm{SD}$ in the individual profile differences). Differences larger than this are therefore indicative of statistically significant bias between IASI and HIPPO. Assuming HIPPO to be correct, biases are most likely either from IASI retrieval error or the representativity of the HIPPO sample of the spatial area sampled by the selected IASI observations. The following points are evident. (1) After applying averaging kernels, the mean bias is $-1.5 \mathrm{ppbv}$ (column average), $3.7 \mathrm{ppbv}(0-$ $6 \mathrm{~km}$ layer average) and $0.24 \mathrm{ppbv}(6-12 \mathrm{~km}$ layer average). As previously noted, averaging kernels have most impact in the Northern Hemisphere (where the prior methane is bi- ased particularly low). (2) The SD in the difference is similar whether or not averaging kernels are applied and is almost always slightly smaller (21-41 ppbv, depending on layer) than the reported ESD (27-47 ppbv) (summaries of the SDs are given for each layer separately in the caption in each panel of Fig. 17). This is not surprising as the ESD includes significant smoothing error, which will not manifest entirely as (quasi) random variability in the agreement between IASI and HIPPO. (3) There is some latitude dependence in the bias, particularly in the lower-tropospheric layer (still mainly within $\pm 20 \mathrm{ppbv}$ ). In particular, IASI seems to underestimate in the tropics. This behaviour is similar to that found between 

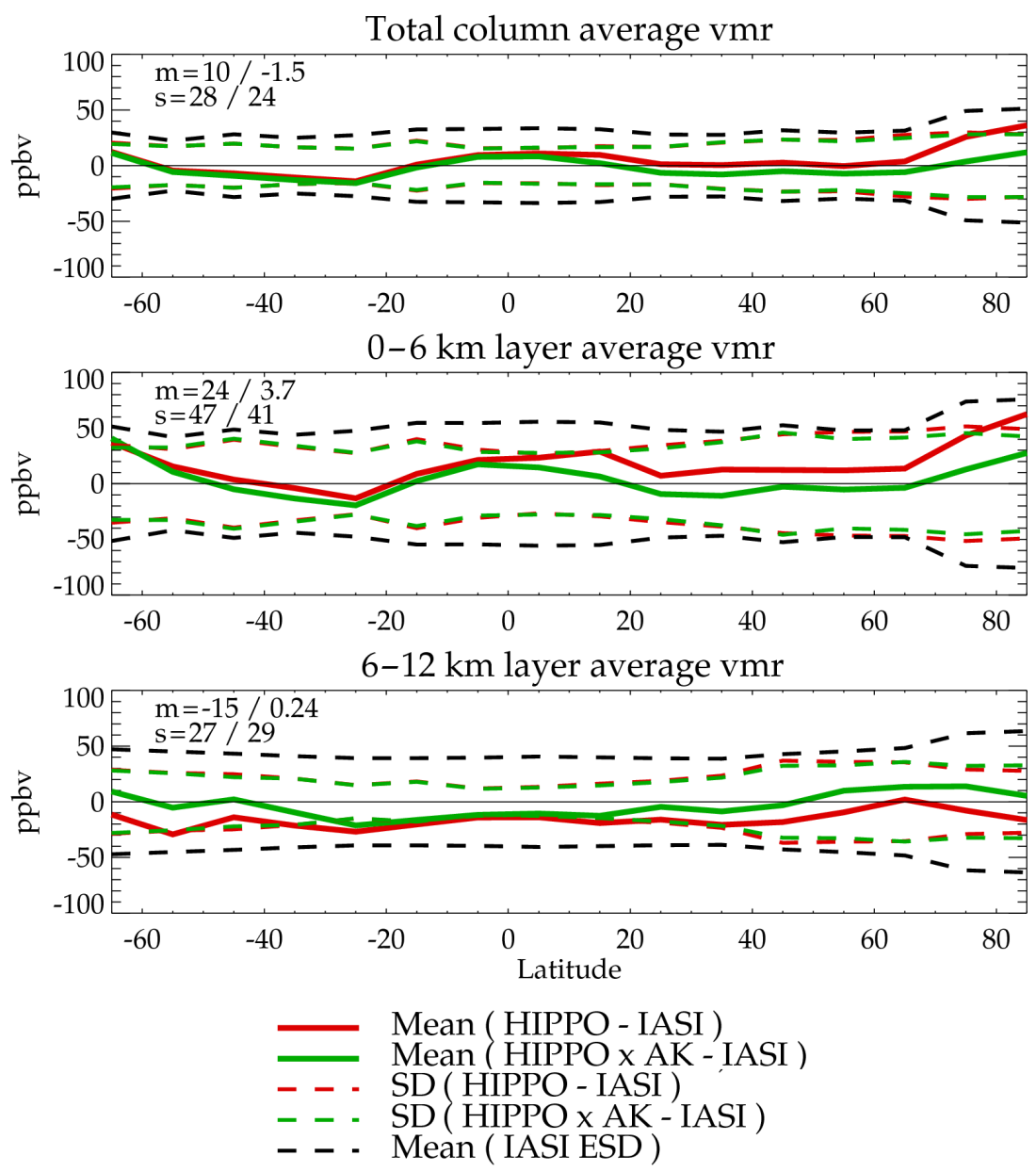

Figure 17. Summary of the differences between IASI and HIPPO for all five HIPPO flight campaigns. Results are presented averaged into $10^{\circ}$ latitude bins. As indicated in the legend, solid lines show the mean difference between IASI and HIPPO (with (green) and without (red) IASI averaging kernels being applied to HIPPO data). Corresponding dashed lines show the standard deviation of the individual IASI/HIPPO matches about the mean difference. Black dashed lines show the mean of the IASI estimated SD (ESD) on individual soundings. Figures in the top left of each panel show the mean difference $(m)$ over all matches and the standard deviation of the individual matches about the mean with and without application of IASI averaging kernels to HIPPO data.

IASI and GOSAT column averages over the tropical oceans, as noted in Sect. 5.3.

\section{Summary and conclusions}

This paper reports a retrieval scheme for IASI developed at the RAL, which, by fitting measured brightness temperature spectra in the $1232-1288 \mathrm{~cm}^{-1}$ interval to RMS precision of $<0.1 \mathrm{~K}$, is capable of extracting information on two independent layers centred in the upper and lower troposphere. Sensitivity near the surface depends upon thermal contrast with the surface and therefore the temperature structure of the lower atmosphere and surface conditions. A particular feature of this scheme is to model and fix $\mathrm{N}_{2} \mathrm{O}$ profiles so that measurement of its absorption features in the same spectral band as methane provide information to co-retrieved effective cloud fraction and height, substantially improving methane retrieval precision by mitigating the effects of residual cloud. The use of the RTTOV10 forward model makes the scheme sufficiently fast on the JASMIN computer infrastructure at RAL to also run in near-real time. The complete IASI MetOp-A record 2007-2015 has been processed, and this 8year global dataset is publically available from the CEDA (Siddans, 2016).

The dataset has been extensively assessed by comparison to independent results from the MACC-II reanalysis based on GHG inversion and to correlative observations from the GOSAT satellite instrument, the TCCON surface network and pole-to-pole height-latitude transects from the HIPPO campaigns. Taken together, these comparisons indicate quasi-random errors of $\sim 20-40 \mathrm{ppbv}$ on individual IASI-retrieved column averages, in line with the ESD provided with each retrieval. Random errors on the estimated 
upper-tropospheric layer average are $\sim 30-40 \mathrm{ppbv}$; those on the lower-tropospheric layer average are more variable with observing conditions (particularly land-atmosphere temperature contrast), in the range of $20-100 \mathrm{ppbv}$. The estimated random errors in the layer averages are supported by the comparisons to HIPPO. After spatial and temporal averaging, and accounting for the vertical sensitivity of the IASI column average, systematic differences with the other datasets are typically $<10 \mathrm{ppbv}$ regionally and $<5 \mathrm{ppbv}$ globally. A systematic bias compared to MACC of around $20 \mathrm{ppbv}$ is found in the Southern Hemisphere, which may be associated with underestimated emissions from Australia in MACC (such a bias is not observed in comparisons to TCCON).

The IASI retrieval is shown to capture the secular increase from 2007 to 2015 and seasonal variations of methane, yielding regional time series with correlations of typically $0.8-0.9$ with respect to the MACC-II GHG inversion, in which surface fluxes were estimated from assimilation of NOAA flask measurements ${ }^{14}$. Furthermore, lower- and upper-tropospheric layer averages have been shown to reproduce much of the seasonal variations predicted by MACC and the extent to which seasonal cycles differ in the two layers, supporting the assertion that IASI can recover two independent pieces of information, in the tropics and midlatitudes. At high latitudes, over particularly cold surfaces, the sensitivity near the ground is reduced, and the heightresolved information becomes limited. The ability to resolve two layers is also supported by comparisons with HIPPO, and is fully in line with the formal estimate of 2 degrees of freedom for the retrieved vertical profile (under most observing conditions away from the poles).

It is important to take into account the sensitivity of the IASI retrievals, as characterised by the averaging kernels, and this is particularly the case at high latitudes and when considering the lower-tropospheric layer. If not taken into account, IASI column averages appear negatively biased at high northern latitudes due to the influence of the prior and systematically low prior value in the troposphere.

This paper focuses on evaluation of the retrieval on relatively coarse spatial and temporal scales. IASI has a spatial resolution of $12 \mathrm{~km}$, as determined by the fields of view of its individual detectors, and therefore has potential for resolving structure on that scale, including discrete emission sources. We note here that the current RAL scheme is limited at fine spatial scales by errors in representation of surface and atmospheric temperature (particularly in mountainous areas) and surface emissivity. These are expected to be mitigated significantly by using temperature and humidity profiles and surface spectral emissivity jointly pre-retrieved

\footnotetext{
${ }^{14}$ After 2013, GOSAT column average data were assimilated in addition to NOAA flask data.
}

from IASI/MHS/AMSU ${ }^{15}$, which is being investigated in depth at present.

Though it does not clearly emerge from the comparisons shown here, we note that users of the data should be cautious when using IASI methane retrievals in the presence of elevated sulphate aerosol, which is known to have significant spectral dependence in the $1232-1288 \mathrm{~cm}^{-1}$ range used by this retrieval (Boer, 2013; Clarisse, 2013). Anomalies in methane retrievals have been noted which may be related to the eruptions of Sarychev in 2009 and Calbuco in 2015.

The scheme makes empirical corrections for discrepancies apparent between line-by-line modelled spectra and IASI observations. These discrepancies do not seem to be resolved by updates in HITRAN 2010 or the line-mixing approach used by LBLRTM. Further work is therefore needed to better understand the spectroscopy of methane and/or spectral interferents in this range.

IASI also measures methane in the 3.7 micron spectral region. During the daytime, measurements in this range include a large surface-reflected solar contribution which contains information on near-surface methane, which is complementary to that obtained from the 7.9 micron band. The potential to practically exploit this additional sensitivity is currently being investigated in depth.

This paper demonstrates that through IASI on MetOp$\mathrm{A}$ and $\mathrm{B}$, as currently in orbit, and $\mathrm{C}$, due for launch in $2018 / 19$, to be followed by IASI-NG on the MetOp-SG series 2020-40, the global, height-resolved methane distribution can be monitored over several decades to investigate variability caused by natural and anthropogenic emissions and composition-climate interactions.

Data availability. The IASI methane data described in this paper are publically available from the UK Centre for Environmental Data Analysis (CEDA) data archive (Siddans, 2016). Access to meteorological reanalysis data from ECMWF and IASI Level-1 data, along with JASMIN computer infrastructure, has also been provided by the CEDA.

TCCON data were obtained from the TCCON Data Archive, hosted by the Carbon Dioxide Information Analysis Center (CDIAC) (http://www.tccon.caltech.edu/).

HIPPO data were obtained from Carbon Dioxide Information Analysis Center (CDIAC) HIPPO Data Archive (http://hippo.ornl. gov/).

MACC-II GHG inversion data were obtained from the ECMWF (http://apps.ecmwf.int/datasets/data/macc-ghg-inversions/).

GOSAT data used here were provided by the ESA GHG CCI project (http://www.esa-ghg-cci.org).

Competing interests. The authors declare that they have no conflict of interest.

\footnotetext{
${ }^{15}$ A new version of the methane retrieval scheme which works on this basis is at an advanced stage of development.
} 
Acknowledgements. This work has been funded by the UK Natural Environment Research Council (NERC) through the National Centre for Earth Observation (NCEO) and the strategic programme "Greenhouse Gases UK and Global Emissions" (GAUGE). Work has also been partly funded by a EUMETSAT study (contract no. EUM/CO/14/4600001315/RM).

Robert Parker and Hartmut Boesch are funded by NCEO and ESA GHG-CCI; Robert Parker is also funded by an ESA Living Planet Fellowship. We thank the Japanese Aerospace Exploration Agency, National Institute for Environmental Studies and the Ministry of Environment for the GOSAT data and their continuous support as part of the Joint Research Agreement. This research used the ALICE High Performance Computing Facility at the University of Leicester.

Edited by: John Worden

Reviewed by: two anonymous referees

\section{References}

Alvarado, M. J., Payne, V. H., Cady-Pereira, K. E., Hegarty, J. D., Kulawik, S. S., Wecht, K. J., Worden, J. R., Pittman, J. V., and Wofsy, S. C.: Impacts of updated spectroscopy on thermal infrared retrievals of methane evaluated with HIPPO data, Atmos. Meas. Tech., 8, 965-985, https://doi.org/10.5194/amt-8965-2015, 2015.

Bergamaschi, P., Houweling, S., Segers, A., Krol, M., Frankenberg, C., Scheepmaker, R. A., Dlugokencky, E., Wofsy, S. C., Kort, E. A., Sweeney, C., Schuck, T., Brenninkmeijer, C., Chen, H., Beck, V., and Gerbig, C.: Atmospheric $\mathrm{CH}_{4}$ in the first decade of the 21st century: inverse modeling analysis using SCIAMACHY satellite retrievals and NOAA surface measurements, J. Geophys. Res.-Atmos., 118, 7350-7369, https://doi.org/10.1002/jgrd.50480, 2013.

Blumenstock, T., Hase, F., Schneider, M., García, O. E., and Sepúlveda, E.: TCCON data from Izana, Tenerife, Spain, Release GGG2014R0. TCCON data archive, hosted by the Carbon Dioxide Information Analysis Center, Oak Ridge National Laboratory, Oak Ridge, Tennessee, USA, https://doi.org/10.14291/tccon.ggg2014.izana01.R0/1149295, 2014.

Blumstein, D., Chalon, G., Carlier, T., Buil, C., Hébert, P., Maciaszek, T., Ponce, G., Phulpin, T., Tournier, B., Siméoni, D., Astruc, P., Clauss, A., Kayal, G., and Jegou, R.: IASI instrument: technical overview and measured performances, P. Soc. PhotoOpt. Ins., 5543, 196-207, https://doi.org/10.1117/12.560907, 2004.

Boera, G. J., Sokolika, I. N., and Martin, S. T.: Infrared optical constants of aqueous sulfate-nitrate-ammonium multi-component tropospheric aerosols from attenuated total reflectance measurements - Part I: Results and analysis of spectral absorbing features, J. Quant. Spectrosc. Ra., 108, 17-38, 2007.

Buchwitz, M., de Beek, R., Burrows, J. P., Bovensmann, H., Warneke, T., Notholt, J., Meirink, J. F., Goede, A. P. H., Bergamaschi, P., Körner, S., Heimann, M., and Schulz, A.: Atmospheric methane and carbon dioxide from SCIAMACHY satellite data: initial comparison with chemistry and transport models,
Atmos. Chem. Phys., 5, 941-962, https://doi.org/10.5194/acp-5941-2005, 2005.

Buchwitz, M., Reuter, M., Schneising, O., Boesch, H., Guerlet, S., Dils, B., Aben, I., Armante, R., Bergamaschi, P., Blumenstock, T., Bovensmann, H., Brunner, D., Buchmann, B., Burrows, J. P., Butz, A., Chédin, A., Chevallier, F., Crevoisier, C. D., Deutscher, N. M., Frankenberg, C., Hase, F., Hasekamp, O. P., Heymann, J., Kaminski, T., Laeng, A., Lichtenberg, G., De Mazière, M., Noël, S., Notholt, J., Orphal, J., Popp, C., Parker, R., Scholze, M., Sussmann, R., Stiller, G. P., Warneke, T., Zehner, C., Bril, A., Crisp, D., Griffith, D. W. T., Kuze, A., O'Dell, C., Oshchepkov, S., Sherlock, V., Suto, H., Wennberg, P., Wunch, D., Yokota, T., and Yoshida, Y.: The Greenhouse Gas Climate Change Initiative (GHG-CCI): comparison and quality assessment of near-surface-sensitive satellite-derived $\mathrm{CO}_{2}$ and $\mathrm{CH}_{4}$ global data sets, Remote Sens. Environ., 162, 344-362, https://doi.org/10.1016/j.rse.2013.04.024, 2015.

Butz, A., Hasekamp, O. P., Frankenberg, C., Vidot, J., and Aben, I.: $\mathrm{CH}_{4}$ retrievals from space-based solar backscatter measurements: Performance evaluation against simulated aerosol and cirrus loaded scenes, J. Geophys. Res., 115, D24302, https://doi.org/10.1029/2010JD014514, 2010.

Collard, A. D.: Selection of IASI channels for use in numerical weather prediction, Q. J. Roy. Meteor. Soc., 133, 1977-1991, 2007.

Crevoisier, C., Nobileau, D., Fiore, A. M., Armante, R., Chédin, A., and Scott, N. A.: Tropospheric methane in the tropics - first year from IASI hyperspectral infrared observations, Atmos. Chem. Phys., 9, 6337-6350, https://doi.org/10.5194/acp-9-6337-2009, 2009.

Crevoisier, C., Nobileau, D., Armante, R., Crépeau, L., Machida, T., Sawa, Y., Matsueda, H., Schuck, T., Thonat, T., Pernin, J., Scott, N. A., and Chédin, A.: The 2007-2011 evolution of tropical methane in the mid-troposphere as seen from space by MetOp-A/IASI, Atmos. Chem. Phys., 13, 4279-4289, https://doi.org/10.5194/acp-13-4279-2013, 2013.

Crisp, D., Fisher, B. M., O'Dell, C., Frankenberg, C., Basilio, R., Bösch, H., Brown, L. R., Castano, R., Connor, B., Deutscher, N. M., Eldering, A., Griffith, D., Gunson, M., Kuze, A., Mandrake, L., McDuffie, J., Messerschmidt, J., Miller, C. E., Morino, I., Natraj, V., Notholt, J., O’Brien, D. M., Oyafuso, F., Polonsky, I., Robinson, J., Salawitch, R., Sherlock, V., Smyth, M., Suto, H., Taylor, T. E., Thompson, D. R., Wennberg, P. O., Wunch, D., and Yung, Y. L.: The ACOS $\mathrm{CO}_{2}$ retrieval algorithm - Part II: Global $\mathrm{X}_{\mathrm{CO}_{2}}$ data characterization, Atmos. Meas. Tech., 5, 687707, https://doi.org/10.5194/amt-5-687-2012, 2012.

De Maziere, M., Sha, M. K., Desmet, F., Hermans, C., Scolas, F., Kumps, N., Metzger, J.-M., Duflot, V., and Cammas, J.-P.: TCCON data from Reunion Island (La Reunion), France, Release GGG2014R0. TCCON data archive, hosted by the Carbon Dioxide Information Analysis Center, Oak Ridge National Laboratory, Oak Ridge, Tennessee, USA, https://doi.org/10.14291/tccon.ggg2014.reunion01.R0/1149288, 2014.

Dee, D. P., Uppala, S. M., Simmons, A. J., Berrisford, P., Poli, P., Kobayashi, S., Andrae, U., Balmaseda, M. A., Balsamo, G., Bauer, P., Bechtold, P., Beljaars, A. C. M., van de Berg, L., Bidlot, J., Bormann, N., Delsol, C., Dragani, R., Fuentes, M., Geer, A. J., Haimberger, L., Healy, S. B., Hersbach, H., 
Holm, E. V., Isaksen, L., Kallberg, P., Köhler, M., Matricardi, M., McNally, A. P., Monge-Sanz, B. M., Morcrette, J.-J., Park, B.K., Peubey, C., de Rosnay, P., Tavolato, C., Thepaut, J.-N., and Vitart, F.: The ERA-Interim reanalysis: configuration and performance of the data assimilation system, Q. J. Roy. Meteor. Soc., 137, 553-597, 2011.

Deutscher, N., Notholt, J., Messerschmidt, J., Weinzierl, C., Warneke, T., Petri, C., Grupe, P., and Katrynski, K.: TCCON data from Bialystok, Poland, Release GGG2014R1. TCCON data archive, hosted by the Carbon Dioxide Information Analysis Center, Oak Ridge National Laboratory, Oak Ridge, Tennessee, USA, https://doi.org/10.14291/tccon.ggg2014.bialystok01.R1/1183984, 2014

Dubey, M., Henderson, B., Green, D., Butterfield, Z., KeppelAleks, G., Allen, N., Blavier, J.-F., Roehl, C., Wunch, D., and Lindenmaier, R.: TCCON data from Manaus, Brazil, Release GGG2014R0. TCCON data archive, hosted by the Carbon Dioxide Information Analysis Center, Oak Ridge National Laboratory, Oak Ridge, Tennessee, USA, https://doi.org/10.14291/tccon.ggg2014.manaus01.R0/1149274, 2014a.

Dubey, M., Lindenmaier, R., Henderson, B., Green, D., Allen, N., Roehl, C., Blavier, J.-F., Butterfield, Z., Love, S., Hamelmann, J., and Wunch, D.: TCCON data from Four Corners, NM, USA, Release GGG2014R0. TCCON data archive, hosted by the Carbon Dioxide Information Analysis Center, Oak Ridge National Laboratory, Oak Ridge, Tennessee, USA, https://doi.org/10.14291/tccon.ggg2014.fourcorners01.R0/1149272, 2014b.

Dudhia, A.: The Reference Forward Model (RFM), J. Quant. Spectrosc. Ra., 186, 243-253, https://doi.org/10.1016/j.jqsrt.2016.06.018, 2016.

Eldering, A., Kulawik, S. S., Worden, J., Bowman, K., and Osterman, G.: Implementation of cloud retrievals for TES atmospheric retrievals: 2 . Characterization of cloud top pressure and effective optical depth retrievals, J. Geophys. Res, 113, D16S37, https://doi.org/10.1029/2007JD008858, 2008.

Feist, D. G., Arnold, S. G., John, N., and Geibel, M. C.: TCCON data from Ascension Island, Saint Helena, Ascension and Tristan da Cunha, Release GGG2014R0. TCCON data archive, hosted by the Carbon Dioxide Information Analysis Center, Oak Ridge National Laboratory, Oak Ridge, Tennessee, USA, https://doi.org/10.14291/tccon.ggg2014.ascension01.R0/1149285, 2014

Frankenberg, C., Aben, I., Bergamaschi, P., Dlugokencky, E. J., van Hees, R., Houweling, S., van der Meer, P., Snel, R., and Tol, P.: Global column averaged methane mixing ratios from 2003 to 2009 as derived from SCIAMACHY: Trends and variability, J. Geophys. Res., 116, D04302, https://doi.org/10.1029/2010JD014849, 2011.

Fraser, A., Palmer, P. I., Feng, L., Boesch, H., Cogan, A., Parker, R., Dlugokencky, E. J., Fraser, P. J., Krummel, P. B., Langenfelds, R. L., O'Doherty, S., Prinn, R. G., Steele, L. P., van der Schoot, M., and Weiss, R. F.: Estimating regional methane surface fluxes: the relative importance of surface and GOSAT mole fraction measurements, Atmos. Chem. Phys., 13, 5697-5713, https://doi.org/10.5194/acp-13-5697-2013, 2013.
Griffith, D. W. T., Deutscher, N., Velazco, V. A., Wennberg, P. O., Yavin, Y., Keppel Aleks, G., Washenfelder, R., Toon, G. C., Blavier, J.-F., Murphy, C., Jones, N., Kettlewell, G., Connor, B., Macatangay, R., Roehl, C., Ryczek, M., Glowacki, J., Culgan, T., and Bryant, G.: TCCON data from Darwin, Australia, Release GGG2014R0. TCCON data archive, hosted by the Carbon Dioxide Information Analysis Center, Oak Ridge National Laboratory, Oak Ridge, Tennessee, USA, https://doi.org/10.14291/tccon.ggg2014.darwin01.R0/1149290, 2014a.

Griffith, D. W. T., Velazco, V. A., Deutscher, N., Murphy, C., Jones, N., Wilson, S., Macatangay, R., Kettlewell, G., Buchholz, R. R., and Riggenbach, M.: TCCON data from Wollongong, Australia, Release GGG2014R0. TCCON data archive, hosted by the Carbon Dioxide Information Analysis Center, Oak Ridge National Laboratory, Oak Ridge, Tennessee, USA, https://doi.org/10.14291/tccon.ggg2014.wollongong01.R0/1149291, $2014 b$.

Gurney, K. R., Law, R. M., Denning, A. S., Rayner, P. J., Baker, D., Bousquet, P., Bruhwiler, L., Chen, Y.-H., Ciais, P., Fan, S., Fung, I. Y., Gloor, M., Heimann, M., Higuchi, K., John, J., Maki, T., Maksyutov, S., Masarie, K., Peylin, P., Prather, M., Pak, B. C., Randerson, J., Sarmiento, J., Taguchi, S., Takahashi, T., and Yuen, C.-W.: Towards robust regional estimates of $\mathrm{CO}_{2}$ sources and sinks using atmospheric transport models, Nature, 415, 626-630, https://doi.org/10.1038/415626a, 2002.

Hase, F., Blumenstock, T., Dohe, S., Groß, J., and Kiel, M.: TCCON data from Karlsruhe, Germany, Release GGG2014R1. TCCON data archive, hosted by the Carbon Dioxide Information Analysis Center, Oak Ridge National Laboratory, Oak Ridge, Tennessee, USA, https://doi.org/10.14291/tccon.ggg2014.karlsruhe01.R1/1182416, 2014.

Hopkins, F. M., Kort, E. A., Bush, S. E., Ehleringer, J. R., Lai, C.-T., Blake, D. R., and Randerson, J. T.: Spatial patterns and source attribution of urban methane in the Los Angeles Basin, J. Geophys. Res.-Atmos., 121, 2490-2507, https://doi.org/10.1002/2015JD024429, 2016.

IPCC, Climate Change 2013: The Physical Science Basis. Contribution of Working Group I to the Fifth Assessment Report of the Intergovernmental Panel on Climate Change, edited by: Stocker, T. F., Qin, D., Plattner, G.-K., Tignor, M., Allen, S. K., Boschung, J., Nauels, A., Xia, Y., Bex, V., and Midgley, P. M., Cambridge University Press, Cambridge, UK and New York, NY, USA, 1535 pp., https://doi.org/10.1017/CBO9781107415324, 2013.

Iraci, L., Podolske, J., Hillyard, P., Roehl, C., Wennberg, P. O., Blavier, J.-F., Landeros, J., Allen, N., Wunch, D., Zavaleta, J., Quigley, E., Osterman, G., Albertson, R., Dunwoody, K., and Boyden, H.: TCCON data from Armstrong Flight Research Center, Edwards, CA, USA, Release GGG2014R0. TCCON data archive, hosted by the Carbon Dioxide Information Analysis Center, Oak Ridge National Laboratory, Oak Ridge, Tennessee, USA, https://doi.org/10.14291/tccon.ggg2014.edwards01.R0/1149289, 2014a.

Iraci, L., Podolske, J., Hillyard, P., Roehl, C., Wennberg, P. O., Blavier, J.-F., Landeros, J., Allen, N., Wunch, D., Zavaleta, J., Quigley, E., Osterman, G., Barrow, E., and Barney, J.: 
TCCON data from Indianapolis, Indiana, USA, Release GGG2014R0. TCCON data archive, hosted by the Carbon Dioxide Information Analysis Center, Oak Ridge National Laboratory, Oak Ridge, Tennessee, USA, https://doi.org/10.14291/tccon.ggg2014.indianapolis01.R0/1149164, 2014b.

Jones, A., Walker, K. A., Jin, J. J., Taylor, J. R., Boone, C. D., Bernath, P. F., Brohede, S., Manney, G. L., McLeod, S., Hughes, R., and Daffer, W. H.: Technical Note: A trace gas climatology derived from the Atmospheric Chemistry Experiment Fourier Transform Spectrometer (ACE-FTS) data set, Atmos. Chem. Phys., 12, 5207-5220, https://doi.org/10.5194/acp12-5207-2012, 2012.

Kerridge, B. J., Siddans, R., Waterfall, A., Latter, B., Miles, G., Reburn, J., Murtagh, D., Eriksson, P., Urban, J., Lossow, S., van Weele, M., Riese, M., Hoffmann, L., Orphal, J., Preusse, P., Höpfner, M., Friedl-Vallon, F., Glatthor, N., Kleinert, A., Dudhia, A., McConnell, J., Semeniuk, K., Kaminski, J., and Lupu, A.: PREMIER Consolidation of Requirements and Synergistic Algorithms (CORSA) Study, Final Report, ESA contract 4200022848/09/NL/CT, 2012.

Kirschke, S., Bousquet, P., Ciais, P., Saunois, M., Canadell, J. G., Dlugokencky, E. J., Bergamaschi, P., Bergmann, D., Blake, D. R., Bruhwiler, L., Cameron-Smith, P., Castaldi, S., Chevallier, F., Feng, L., Fraser, A., Heimann, M., Hodson, E. L., Houweling, S., Josse, B., Fraser, P. J., Krummel, P. B., Lamarque, J.-F., Langenfelds, R. L., Le Quéré, C., Naik, V., O’Doherty, S., Palmer, P. I., Pison, I., Plummer, D., Poulter, B., Prinn, R. G., Rigby, M., Ringeval, B., Santini, M., Schmidt, M., Shindell, D. T., Simpson, I. J., Spahni, R., Steele, L. P., Strode, S. A., Sudo, K., Szopa, S., van der Werf, G. R., Voulgarakis, A., van Weele, M., Weiss, R. F., Williams, J. E., and Zeng, G.: Three decades of global methane sources and sinks, Nat. Geosci., 6, 813-823, 2013

Kivi, R., Heikkinen, P., and Kyro, E.: TCCON data from Sodankyla, Finland, Release GGG2014R0. TCCON data archive, hosted by the Carbon Dioxide Information Analysis Center, Oak Ridge National Laboratory, Oak Ridge, Tennessee, USA, https://doi.org/10.14291/tccon.ggg2014.sodankyla01.R0/1149280, 2014.

Kort, E. A., Frankenberg, C., Costigan, K. R., Lindenmaier, R., Dubey, M. K., and Wunch, D.: Four corners: the largest US methane anomaly viewed from space, Geophys. Res. Lett., 41, 6898-6903, https://doi.org/10.1002/2014GL061503, 2014.

Kulawik, S. S., Worden, J., Eldering, A., Bowman, K., Gunson, M., Osterman, G. B., Zhang, L., Clough, S. A., Shephard, M. W., and Beer, R.: Implementation of cloud retrievals for Tropospheric Emission Spectrometer (TES) atmospheric retrievals: Part 1. Description and characterization of errors on trace gas retrievals, J. Geophys. Res., 111, D24204, https://doi.org/10.1029/2005JD006733, 2006.

Kuze, A., Suto, H., Shiomi, K., Nakajima, M., and Hamazaki, T.: On-orbit performance and level 1 data processing of TANSOFTS and CAI on GOSAT, Proc. SPIE, Sensors, Systems, and Next-Generation Satellites XIII, 7474, 74740I, https://doi.org/10.1117/12.830152, 2009.

Kuze, A., Suto, H., Shiomi, K., Kawakami, S., Tanaka, M., Ueda, Y., Deguchi, A., Yoshida, J., Yamamoto, Y., Kataoka, F., Taylor, T. E., and Buijs, H. L.: Update on GOSAT TANSO-
FTS performance, operations, and data products after more than 6 years in space, Atmos. Meas. Tech., 9, 2445-2461, https://doi.org/10.5194/amt-9-2445-2016, 2016.

Lary, D. J., Chipperfield, M. P., Pyle, J. A., Norton, W. A., and Riishøjgaard, L. P.: Three-dimensional tracer initialization and general diagnostics using equivalent PV latitude-potentialtemperature coordinates, Q. J. Roy. Meteor. Soc., 121, 187-210, https://doi.org/10.1002/qj.49712152109, 1995.

Massart, S., Agusti-Panareda, A., Aben, I., Butz, A., Chevallier, F., Crevoisier, C., Engelen, R., Frankenberg, C., and Hasekamp, O. Assimilation of atmospheric methane products into the MACCII system: from SCIAMACHY to TANSO and IASI, Atmos. Chem. Phys., 14, 6139-6158, https://doi.org/10.5194/acp-146139-2014, 2014.

Morino, I., Matsuzaki, T., and Shishime, A.: TCCON data from Tsukuba, Ibaraki, Japan, 125HR, Release GGG2014R0. TCCON data archive, hosted by the Carbon Dioxide Information Analysis Center, Oak Ridge National Laboratory, Oak Ridge, Tennessee, USA, https://doi.org/10.14291/tccon.ggg2014.tsukuba02.R0/1149301, 2014a.

Morino, I., Yokozeki, N., Matzuzaki, T., and Shishime, A.: TCCON data from Rikubetsu, Hokkaido, Japan, Release GGG2014R0. TCCON data archive, hosted by the Carbon Dioxide Information Analysis Center, Oak Ridge National Laboratory, Oak Ridge, Tennessee, USA, https://doi.org/10.14291/tccon.ggg2014.rikubetsu01.R0/1149282, 2014b.

Nisbet, E. G., Dlugokencky, E. J., and Bousquet, P.: Methane on the rise - again, Science, 343, 493-495, 2014.

Notholt, J., Petri, C., Warneke, T., Deutscher, N., Buschmann, M., Weinzierl, C., Macatangay, R., and Grupe, P.: TCCON data from Bremen, Germany, Release GGG2014R0. TCCON data archive, hosted by the Carbon Dioxide Information Analysis Center, Oak Ridge National Laboratory, Oak Ridge, Tennessee, USA, https://doi.org/10.14291/tccon.ggg2014.bremen01.R0/1149275, 2014.

Parker, R., Boesch, H., Cogan, A., Fraser, A., Feng, L., Palmer, P. I., Messerschmidt, J., Deutscher, N., Griffith, D. W. T., Notholt, J., Wennberg, P. O., and Wunch, D.: Methane observations from the Greenhouse Gases Observing SATellite: Comparison to groundbased TCCON data and model calculations, Geophys. Res. Lett., 38, L15807, https://doi.org/10.1029/2011GL047871, 2011.

Parker, R. J., Boesch, H., Byckling, K., Webb, A. J., Palmer, P. I., Feng, L., Bergamaschi, P., Chevallier, F., Notholt, J., Deutscher, N., Warneke, T., Hase, F., Sussmann, R., Kawakami, S., Kivi, R., Griffith, D. W. T., and Velazco, V.: Assessing 5 years of GOSAT Proxy $\mathrm{XCH}_{4}$ data and associated uncertainties, Atmos. Meas. Tech., 8, 4785-4801, https://doi.org/10.5194/amt-8-4785-2015, 2015.

Poulsen, C. A., Siddans, R., Thomas, G. E., Sayer, A. M., Grainger, R. G., Campmany, E., Dean, S. M., Arnold, C., and Watts, P. D.: Cloud retrievals from satellite data using optimal estimation: evaluation and application to ATSR, Atmos. Meas. Tech., 5, 1889-1910, https://doi.org/10.5194/amt-5-1889-2012, 2012.

Razavi, A., Clerbaux, C., Wespes, C., Clarisse, L., Hurtmans, D., Payan, S., Camy-Peyret, C., and Coheur, P. F.: Characterization of methane retrievals from the IASI space-borne sounder, Atmos. 
Chem. Phys., 9, 7889-7899, https://doi.org/10.5194/acp-9-78892009, 2009.

Rigby, M., Prinn, R. G., Fraser, P. J., Simmonds, P. G., Langenfelds, R. L., Huang, J., Cunnold, D. M., Steele, L. P., Krummel, P. B., Weiss, R. F., O'Doherty, S., Salameh, P. K., Wang, H. J., Harth, C. M., Muhle, J., and Porter, L. W.: Renewed growth of atmospheric methane, Geophys. Res. Lett., 35, L22805, https://doi.org/10.1029/2008GL036037, 2008.

Rodgers, C. D.: Inverse Methods for Atmospheric Sounding: Theory and Practice, Series on Atmospheric, Oceanic and Planetary Physics - Vol. 2, edited by: Taylor, F. W., World Scientific Publishing Co., 2000.

Seemann, S. W., Borbas, E. E., Knuteson, R. O., Stephenson, G. R., and Huang, H.-L.: Development of a Global Infrared Land Surface Emissivity Database for Application to Clear Sky Sounding Retrievals from Multispectral Satellite Radiance Measurements, J. Appl. Meteorol. Clim., 47, 108-123, 2008.

Sherlock, V., Connor, B., Robinson, J., Shiona, H., Smale, D., and Pollard, D.: TCCON data from Lauder, New Zealand, 120HR, Release GGG2014R0. TCCON data archive, hosted by the Carbon Dioxide Information Analysis Center, Oak Ridge National Laboratory, Oak Ridge, Tennessee, USA, https://doi.org/10.14291/tccon.ggg2014.lauder01.R0/1149293, 2014a.

Sherlock, V., Connor, B., Robinson, J., Shiona, H., Smale, D., and Pollard, D.: TCCON data from Lauder, New Zealand, 125HR, Release GGG2014R0. TCCON data archive, hosted by the Carbon Dioxide Information Analysis Center, Oak Ridge National Laboratory, Oak Ridge, Tennessee, USA, https://doi.org/10.14291/tccon.ggg2014.lauder02.R0/1149298, 2014b.

Shiomi, K., Kawakami, S., Ohyama, H., Arai, K., Okumura, H., Taura, C., Fukamachi, T., and Sakashita, M.: TCCON data from Saga, Japan, Release GGG2014R0. TCCON data archive, hosted by the Carbon Dioxide Information Analysis Center, Oak Ridge National Laboratory, Oak Ridge, Tennessee, USA, https://doi.org/10.14291/tccon.ggg2014.saga01.R0/1149283, 2014

Siddans, R., Knappett, D., Kerridge, B., Latter, B., Waterfall, A., Hurley, J., and Walker, J.: STFC RAL methane retrievals from IASI on board MetOp-A, version 1.0, Centre for Environmental Data Analysis data archive, https://doi.org/10.5285/B6A84C7389F3-48EC-AEE3-592FEF634E9B, 2016.

Simmons, A. J., Poli, P., Dee, D. P., Berrisford, P., Hersbach, H., Kobayashi, S., and Peubey, C.: Estimating low-frequency variability and trends in atmospheric temperature using ERAInterim, European Centre for Medium Range Weather Forecasts, ERA Report Series 15 - Rev. 1, 2014.

Strong, K., Mendonca, J., Weaver, D., Fogal, P., Drummond, J. R., Batchelor, R., and Lindenmaier, R.: TCCON data from Eureka, Canada, Release GGG2014R0. TCCON data archive, hosted by the Carbon Dioxide Information Analysis Center, Oak Ridge National Laboratory, Oak Ridge, Tennessee, USA, https://doi.org/10.14291/tccon.ggg2014.eureka01.R0/1149271, 2014.

Sussmann, R., Forster, F., Rettinger, M., and Bousquet, P.: Renewed methane increase for five years (2007-2011) observed by solar FTIR spectrometry, Atmos. Chem. Phys., 12, 4885-4891, https://doi.org/10.5194/acp-12-4885-2012, 2012.
Sussmann, R. and Rettinger, M.: TCCON data from Garmisch, Germany, Release GGG2014R0. TCCON data archive, hosted by the Carbon Dioxide Information Analysis Center, Oak Ridge National Laboratory, Oak Ridge, Tennessee, USA, https://doi.org/10.14291/tccon.ggg2014.garmisch01.R0/1149299, 2014.

Te, Y., Jeseck, P., and Janssen, C.: TCCON data from Paris, France, Release GGG2014R0. TCCON data archive, hosted by the Carbon Dioxide Information Analysis Center, Oak Ridge National Laboratory, Oak Ridge, Tennessee, USA, https://doi.org/10.14291/tccon.ggg2014.paris01.R0/1149279, 2014.

von Clarmann, T.: Smoothing error pitfalls, Atmos. Meas. Tech., 7, 3023-3034, https://doi.org/10.5194/amt-7-3023-2014, 2014.

Warneke, T., Messerschmidt, J., Notholt, J., Weinzierl, C., Deutscher, N., Petri, C., Grupe, P., Vuillemin, C., Truong, F., Schmidt, M., Ramonet, M., and Parmentier, E.: TCCON data from Orleans, France, Release GGG2014R0. TCCON data archive, hosted by the Carbon Dioxide Information Analysis Center, Oak Ridge National Laboratory, Oak Ridge, Tennessee, USA, https://doi.org/10.14291/tccon.ggg2014.orleans01.R0/1149276, 2014.

Wecht, K. J., Jacob, D. J., Wofsy, S. C., Kort, E. A., Worden, J. R., Kulawik, S. S., Henze, D. K., Kopacz, M., and Payne, V. H.: Validation of TES methane with HIPPO aircraft observations: implications for inverse modeling of methane sources, Atmos. Chem. Phys., 12, 1823-1832, https://doi.org/10.5194/acp12-1823-2012, 2012.

Wennberg, P. O., Roehl, C., Blavier, J.-F., Wunch, D., Landeros, J., and Allen, N.: TCCON data from Jet Propulsion Laboratory, Pasadena, California, USA, Release GGG2014R0. TCCON data archive, hosted by the Carbon Dioxide Information Analysis Center, Oak Ridge National Laboratory, Oak Ridge, Tennessee, USA, https://doi.org/10.14291/tccon.ggg2014.jp102.R0/1149297, 2014a.

Wennberg, P. O., Roehl, C., Wunch, D., Toon, G. C., Blavier, J.-F., Washenfelder, R., Keppel-Aleks, G., Allen, N., and Ayers, J.: TCCON data from Park Falls, Wisconsin, USA, Release GGG2014R0. TCCON data archive, hosted by the Carbon Dioxide Information Analysis Center, Oak Ridge National Laboratory, Oak Ridge, Tennessee, USA, https://doi.org/10.14291/tccon.ggg2014.parkfalls01.R0/1149161, 2014b.

Wennberg, P. O., Wunch, D., Roehl, C., Blavier, J.-F., Toon, G. C., and Allen, N.: TCCON data from California Institute of Technology, Pasadena, California, USA Release GGG2014R1. TCCON data archive, hosted by the Carbon Dioxide Information Analysis Center, Oak Ridge National Laboratory, Oak Ridge, Tennessee, USA, https://doi.org/10.14291/tccon.ggg2014.pasadena01.R1/1182415, 2014c.

Wennberg, P. O., Wunch, D., Roehl, C., Blavier, J.-F., Toon, G. C., Allen, N., Dowell, P., Teske, K., Martin, C., and Martin, J.: TCCON data from Lamont, Oklahoma, USA, Release GGG2014R0. TCCON data archive, hosted by the Carbon Dioxide Information Analysis Center, Oak Ridge National Laboratory, Oak Ridge, Tennessee, USA, 
https://doi.org/10.14291/tccon.ggg2014.lamont01.R0/1149159, 2014d.

Wennberg, P. O., Wunch, D., Yavin, Y., Toon, G. C., Blavier, J.F., Allen, N., and Keppel-Aleks, G.: TCCON data from Jet Propulsion Laboratory, Pasadena, California, USA, Release GGG2014R0. TCCON data archive, hosted by the Carbon Dioxide Information Analysis Center, Oak Ridge National Laboratory, Oak Ridge, Tennessee, USA, https://doi.org/10.14291/tccon.ggg2014.jp101.R0/1149163, 2014e.

Westbrook, G. K., Thatcher, K. E., Rohling, E. J., Piotrowski, A. M., Pälike, H., Osborne, A. H., Nisbet, E. G., Minshull, T. A., Lanoisellé, M., James, R. H., Huhnerbach, V., Green, D., Fisher, R. E., Crocker, A. J., Chabert, A., Bolton, C., Beszczynska-Möller, A., Berndt, C., and Aquilina, A.: Escape of methane gas from the seabed along the West Spitsbergen continental margin, Geophys. Res. Lett., 36, L15608, https://doi.org/10.1029/2009GL039191, 2009.

Wofsy, S. C., Daube, B. C., Jimenez, R., Kort, E., Pittman, J. V., Park, S., Commane, R., Xiang, B., Santoni, G., Jacob, D., Fisher, J., Pickett-Heaps, C., Wang, H., Wecht, K., Wang, Q.Q., Stephens, B. B., Shertz, S., Watt, A. S., Romashkin, P., Campos, T., Haggerty, J., Cooper, W. A., Rogers, D., Beaton, S., Hendershot, R., Elkins, J. W., Fahey, D. W., Gao, R. S., Moore, F., Montzka, S. A., Schwarz, J. P., Perring, A. E., Hurst, D., Miller, B. R., Sweeney, C., Oltmans, S., Nance, D., Hintsa, E., Dutton, G., Watts, L. A., Spackman, J. R., Rosenlof, K. H., Ray, E. A., Hall, B., Zondlo, M. A., Diao, M., Keeling, R., Bent, J., Atlas, E. L., Lueb, R., and Mahoney, M. J.: HIPPO Merged 10-second Meteorology, Atmospheric Chemistry, Aerosol Data (R_20121129), Carbon Dioxide Information Analysis Center, Oak Ridge National Laboratory, Oak Ridge, Tennessee, USA, https://doi.org/10.3334/CDIAC/hippo_010 (Release 20121129), 2012.

Worden, J., Kulawik, S., Frankenberg, C., Payne, V., Bowman, K., Cady-Peirara, K., Wecht, K., Lee, J.-E., and Noone, D.: Profiles of $\mathrm{CH}_{4}, \mathrm{HDO}, \mathrm{H}_{2} \mathrm{O}$, and $\mathrm{N}_{2} \mathrm{O}$ with improved lower tropospheric vertical resolution from Aura TES radiances, Atmos. Meas. Tech., 5, 397-411, https://doi.org/10.5194/amt-5397-2012, 2012.
Worden, J., Wecht, K., Frankenberg, C., Alvarado, M., Bowman, K., Kort, E., Kulawik, S., Lee, M., Payne, V., and Worden, $\mathrm{H}$.: $\mathrm{CH}_{4}$ and $\mathrm{CO}$ distributions over tropical fires during October 2006 as observed by the Aura TES satellite instrument and modeled by GEOS-Chem, Atmos. Chem. Phys., 13, 3679-3692, https://doi.org/10.5194/acp-13-3679-2013, 2013.

Worden, J. R., Turner, A. J., Bloom, A., Kulawik, S. S., Liu, J., Lee, M., Weidner, R., Bowman, K., Frankenberg, C., Parker, R., and Payne, V. H.: Quantifying lower tropospheric methane concentrations using GOSAT near-IR and TES thermal IR measurements, Atmos. Meas. Tech., 8, 3433-3445, https://doi.org/10.5194/amt-8-3433-2015, 2015.

Wunch, D., Toon, G. C., Blavier, J.-F. L., Washenfelder, R. A., Notholt, J., Connor, B. J., Griffith, D. W. T., Sherlock, V., Wennberg, P. O.: The total carbon column observing network, Philos. T. R. Soc. A, 369, 2087-2112, https://doi.org/10.1098/rsta.2010.0240, 2011.

Xiong, X., Barnet, C., Maddy, E., Sweeney, C., Liu, X., Zhou, L., and Goldberg, M.: Characterization and validation of methane products from the Atmospheric Infrared Sounder (AIRS), J. Geophys. Res., 113, G00A01, https://doi.org/10.1029/2007JG000500, 2008.

Xiong, X., Barnet, C., Maddy, E. S., Gambacorta, A., King, T. S., and Wofsy, S. C.: Mid-upper tropospheric methane retrieval from IASI and its validation, Atmos. Meas. Tech., 6, 2255-2265, https://doi.org/10.5194/amt-6-2255-2013, 2013.

Yoshida, Y., Kikuchi, N., Morino, I., Uchino, O., Oshchepkov, S., Bril, A., Saeki, T., Schutgens, N., Toon, G. C., Wunch, D., Roehl, C. M., Wennberg, P. O., Griffith, D. W. T., Deutscher, N. M., Warneke, T., Notholt, J., Robinson, J., Sherlock, V., Connor, B., Rettinger, M., Sussmann, R., Ahonen, P., Heikkinen, P., Kyrö, E., Mendonca, J., Strong, K., Hase, F., Dohe, S., and Yokota, T.: Improvement of the retrieval algorithm for GOSAT SWIR $\mathrm{XCO}_{2}$ and $\mathrm{XCH}_{4}$ and their validation using TCCON data, Atmos. Meas. Tech., 6, 1533-1547, https://doi.org/10.5194/amt-61533-2013, 2013. 